NBER WORKING PAPER SERIES

\title{
HOW CONSUMERS RESPOND TO ENVIRONMENTAL CERTIFICATION AND THE VALUE OF ENERGY INFORMATION
}

\author{
Sébastien Houde \\ Working Paper 20019 \\ http://www.nber.org/papers/w20019
NATIONAL BUREAU OF ECONOMIC RESEARCH
1050 Massachusetts Avenue
Cambridge, MA 02138
March 2014

\begin{abstract}
An earlier version of this paper was circulated under the title: "How Consumers Respond to Product Certification; A Welfare Analysis of the ENERGY STAR Program". I am indebted to Jim Sweeney, Wes Hartmann, Jon Levin, and John Weyant for all their helpful advice. I would also like to thank Larry Goulder, Matt Harding, Ken Gillingham, Anant Sudarshan, Jim Sallee, Charles Mason, David Rapson, and seminar participants at the Stanford IO lunch, the SEEPAC environmental economics seminar, and the NBER Summer Institute in Environmental and Energy Economics. The views expressed herein are those of the author and do not necessarily reflect the views of the National Bureau of Economic Research.
\end{abstract}

NBER working papers are circulated for discussion and comment purposes. They have not been peerreviewed or been subject to the review by the NBER Board of Directors that accompanies official NBER publications.

(C) 2014 by Sébastien Houde. All rights reserved. Short sections of text, not to exceed two paragraphs, may be quoted without explicit permission provided that full credit, including $\odot$ notice, is given to the source. 
How Consumers Respond to Environmental Certification and the Value of Energy Information Sébastien Houde

NBER Working Paper No. 20019

March 2014

JEL No. D12,D83,L15,Q41,Q50

\begin{abstract}
$\underline{\text { ABSTRACT }}$
The ENERGY STAR certification is a voluntary labeling that favors the adoption of energy efficient products. In the US appliance market, the label is a coarse summary of otherwise readily accessible information. Using micro-data of the US refrigerator market, I develop a structural demand model and find that consumers respond to certification in different ways. Some consumers have a large willingness to pay for the label, well beyond the energy savings associated with certified products; others appear to pay attention to electricity costs, but not to the certification, and still others appear to be insensitive to both electricity costs and ENERGY STAR. The findings suggest that the certification acts as a substitute for more accurate, but complex energy information. Using the structural model, I find that the opportunity cost of having imperfectly informed consumers in the refrigerator market ranges from $\$ 12$ to $\$ 17$ per refrigerator sold.
\end{abstract}

Sébastien Houde 2222 Symons Hall

University of Maryland

Department of Agricultural and Resource Economics

College Park, MD 20742

shoude@umd.edu

An online appendix is available at:

http://www.nber.org/data-appendix/w20019 


\section{Introduction}

The role of certification programs is to address informational market failures, and ultimately help consumers in distinguishing high-quality products from lemons (Akerlof 1970; Viscusi 1978). Theoretical analyses have shown that the welfare effects of certification programs depend on a confluence of factors such as market structure, heterogeneity in consumer preferences, and consumer sophistication (Dranove and Jin 2010). When certification programs come with labeling schemes, the information content of labels may also be an important determinant of welfare. Labels - like advertisements - may affect how consumers perceive and experience goods (Bagwell 2007). Moreover, whether a label provides new information, or summarizes complex, but otherwise available information have different welfare implications.

The goal of this paper is to show how consumers respond to ENERGY STAR (ES), a voluntary certification program managed by the US Environmental Protection Agency (EPA). The main feature of the program consists of a simple labeling scheme (Figure 1(a)) that identifies the most energy efficient products in the marketplace. In several markets, the program complements the mandatory label EnergyGuide (Figure 1(b)), which provides detailed energy information. The rationale of the ES label is to present energy efficiency as a dimension of quality that is simple, easy to assess, and fully salient to consumers.

I propose a structural demand model that captures the various mechanisms by which the certification influences consumers. The model is inspired from classic models of consumer search and information acquisition (e.g., Stigler 1961; McCall 1965; Gabaix et al. 2006). In the same spirit as Sallee (2013), I use a theory of rational attention allocation (Sims 2003) to model why consumers may rely on different pieces of energy information.

The estimation is carried on a large sample of transactions of the US refrigerator market. In addition to rich variation in prices, electricity costs, and financial incentives for purchasing certified products, the sample period includes two natural experiments that provide variation in labeling. The structural model exploits this variation to recover consumer preferences for the ES label, marginal utility of income, discount rate, and propensity to take advantage of rebates. The crucial feature of the model is, however, to recover heterogeneity in the way consumers rely on energy 
information. I find that some consumers rely on the certification and value the label itself well beyond the energy savings associated with certified products, but others rely on a measure of electricity costs and do not value the label highly. A non-negligible fraction of consumers also appears to neither value the certification nor consider electricity costs in their purchase decisions, and this fraction is much larger for lower income households.

The results from the structural estimation are supported by alternative estimators that account for heterogeneity in a more flexible manner. I first show using a simple conditional logit that the coefficients on the ES label and electricity costs are inversely correlated with several demographic variables. In particular, richer and smaller households, where the head is older and educated respond more to electricity costs, but not so much to the label. Using an approach proposed by Fox et al. (2011), I recover a nonparametric join distribution of the coefficients on the ES label and electricity costs, which also shows a clear negative correlation between the two coefficients. Altogether, the data suggest that the certification acts as a substitute for more accurate, but complex energy information.

These results are of primary importance for the design of energy policies that target energy demand. Consumers' inattention to energy efficiency is an often-cited justification for minimum standards. Recent empirical evidence has, however, been mostly confined to the car market (e.g., Klier and Linn 2010; Li, Timmins and von Haefen 2009; Busse, Knittel and Zettelmeyer 2013; Allcott and Wozny 2012), and suggests that inattention to car operating costs may in fact be modest on average. I fill a gap in this literature by explicitly showing how existing labeling policies in the appliance market may overcome inattention, and quantifying the value of energy information. I find that the opportunity cost of having imperfectly informed consumers in the refrigerator market ranges from $\$ 12$ to $\$ 17$ per refrigerator sold, or $\$ 108 \mathrm{M} /$ year to $\$ 153 \mathrm{M} /$ year for the whole market. These latter estimates are more than twice larger the overall program cost of the ES program.

Surprisingly, although ecolabels have become ubiquitous in marketplaces, empirical analyses of such policies have remained scarce (Mason 2013). The structural model contributes to the theoretical work on the topic by developing and testing a theory of how consumers respond to 
environmental certification. It also provides the first estimates of the behavioral effects of the ES program using a revealed preference approach combined with market-level data. ${ }^{1}$

More broadly, this paper contributes to the literature on information-based policies. Arguably, the complexity and economic significance of the appliance purchasing decision pale by comparison to other decisions such as retirement savings, health care plan, nutrition, and school enrollment. In these settings, it is also customary to provide coarse summaries of complex information, by way of grades, rankings, and score cards, for instance. My framework and empirical strategy could be applied to these contexts, and complement other structural estimators (e.g., Abaluck and Gruber 2011; Abaluck 2011; Handel and Kolstad 2013) that aim to explicitly deal with attention allocation and heuristics used in complex choice environments.

The remainder of this paper is organized as follows. Section 2 provides a primer on energy labels for the US appliance market. Section 3 presents a theory of how consumers respond to the ES certification. Section 4 gives an overview of the data, and discusses sources of identification. Section 5 provides preliminary estimates using a simple conditional logit model. Section 6 proceeds to the estimation of the structural model, and section 7 provides an alternative estimator that recovers heterogeneity in the valuation of energy efficiency with minimal structure. The policy analysis is presented in section 8 , and conclusions follow.

\section{A Primer on Energy Labels for the Appliance Market}

In the US appliance market, two different labeling schemes offer energy information to consumers. The EnergyGuide program was established in 1979, and is managed by the Federal Trade Commission. The program covers most types of appliances, and several consumer electronics. The main feature of the program is the requirement that all products offered in the marketplace display prominently a large yellow label with detailed technical information about energy consumption and costs. The content of the EnergyGuide label was revised several times since the inception of the program. In its most recent version (Figure 1(b)), the label displays the annual electricity (or gas)

\footnotetext{
${ }^{1}$ Ward et al. (2011) used an online survey to elicit consumers' willingness to pay for the ES label, and found a positive and significant impact of the label on hypothetical decisions. Recently, Newell and Siikamäki (2013) use an online survey with hypothetical choices and also found that the label has a large impact on choices.
} 
consumption of the product, an estimate of the annual operating cost based on the national average price of energy, and a scale with a cost range of similar products.

ENERGY STAR was established in 1992 by the EPA as a way to complement EnergyGuide. The ES label contains no technical information, and is similar to a simple brand logo (Figure 1(a)). Only products that meet a certain certification have the right to display the label. For certified appliances, the label is often displayed on the product itself, and on the EnergyGuide label.

Historically, the certification requirement for appliances has been binary. ${ }^{2}$ Under this system, the requirement is defined relative to the federal minimum energy efficiency standard. For instance, since April 2008, a full-size refrigerator can be certified if it consumes at least $20 \%$ less electricity than the minimum energy efficiency standard established for this refrigerator model. Because minimum standards vary as a function of the appliance size, and other attributes, the certification requirement does not fix electricity consumption to an absolute level. It is common to find small uncertified appliances that consume less than larger certified appliances.

A crucial feature of the program is that the certification requirements are revised periodically. The EPA revises the stringency of a requirement using various criteria, such as the proportion of certified products offered on the market, the market shares, and the availability of new technologies (McWhinney et al. 2005). The stringency of a requirement is ultimately determined by the EPA upon consultation with different stakeholders, such as manufacturers, part providers, retailers, analysts, and environmental groups. The EPA usually announces a revision one year in advance.

An important institutional feature of the US electricity market is that several electric utilities are subject to regulations that incentivize them to promote energy efficiency measures to consumers. Rebate programs tied to the purchase of ES products have been arguably one of the most popular energy efficiency measures pursued by US electric utilities. The Energy Policy Act of 2005 also established a state rebate program for appliances tied to the ES certification. In 2010-2011, this program was temporarily funded with stimulus funds. Thus, apart from the informational component, financial incentives may play a role in favoring the adoption of certified products.

${ }^{2}$ Since 2011 , the EPA has been experimenting with a multiple tiers system in some product categories. The present paper focuses on the binary system. 


\section{An Information Acquisition Model for Energy-Intensive Durables}

In the context of purchasing an appliance, evaluating the energy cost of each product is arguably a complex and costly task. It requires taking the time to look at the EnergyGuide label, understand the various pieces of information, look up the local electricity prices, and perform mental calculations. A priori, knowledge about the energy cost of each product $j, C_{j}$, is then consider imperfect. A consumer $i$ can learn the value of $C_{j}$ only by incurring a cost $K_{i}\left(e_{i}\right)$, where $e_{i}$ represents the effort to collect and process energy information. Define $\mathcal{I}\left(e_{i}\right)$ as the consumer's knowledge about energy costs for a given level of effort, the expected energy cost of product $j$ at the time of purchase is then defined by: $E\left[C_{j} \mid \mathcal{I}\left(e_{i}\right)\right]$.

In addition of the expected energy cost, consumer $i$ values product $j$ as a function of its quality $\left(\delta_{j}\right)$, price $\left(P_{j}\right)$, whether a product is ES certified or not $\left(D_{j}\right)$, rebate amount $(R)$, and an idiosyncratic taste parameter $\left(\epsilon_{i j}\right)$ :

$$
U_{i j}=\delta_{j}-\eta P_{j}-\theta E\left[C_{j} \mid \mathcal{I}\left(e_{i}\right)\right]+\tau D_{j}+\psi D_{j} \times R+\epsilon_{i j}
$$

where the coefficients: $\eta, \theta, \tau$, and $\psi$ all relate to structural demand parameters. The coefficient on prices $(\eta)$ corresponds to the marginal utility of income, and the ratio of the coefficient on the ES dummy $(\tau)$ and the marginal utility of income $(\tau / \eta)$ corresponds to the marginal willingness to pay for the label itself. If we were able to observe whether a consumer claimed a rebate $R$, and there were no hassle costs associated with claiming a rebate, the coefficient on rebates would match the coefficient on prices, i.e., would be equal to the marginal utility of income. These conditions do not hold in the present application. The coefficient on rebates $(\psi)$ should then be interpreted as an intent to treat estimator (Imbens and Angrist 1994) corresponding to the marginal utility of income multiplied by the probability that a consumer takes advantage of a rebate program. Finally, comparing the coefficient on electricity $\operatorname{costs}(\theta)$ with the coefficient on prices informs about the extent that consumers trade off future electricity costs with the purchase price. Assuming that consumers form time-unvarying expectations about annual electricity costs, and do not account for the effect of depreciation, the coefficient on electricity costs is then a reduced form parameter that 
relates to the discount factor as follows: ${ }^{3}$

$$
\theta=\eta \frac{1-\rho^{L}}{1-\rho},
$$

where $L$ is the lifetime of the durable, and $\rho=1 /(1+r)$ is the discount factor. The estimates of $\eta$ and $\theta$ can then be used to infer a value of an implicit discount rate $r$.

A consumer's purchasing decision is modeled as a two-step process. To begin, a consumer is uncertain about energy costs, the meaning of the certification (noted $S$ ), and whether a product is certified or not. ${ }^{4}$ A consumers observes the quality and the price for each appliance and then decides the amount of effort to collect and process energy information. I assume that choosing the effort level is a discrete choice with three possible outcomes. A consumer may collect and processes enough information to form accurate expectations about the energy costs associated with each option, and thus make a purchase decision perfectly informed (noted $e=I$ ). In this case, $E\left[C_{j} \mid \mathcal{I}\left(e_{i}=I\right)\right]=C_{j}$, where $C_{j}$ is an accurate forecast of the energy costs of product $j$. Alternatively, a consumer may only collect information related to the certification (noted $e=E S$ ). He will then learn the true meaning of the certification and which products are certified, but not the exact energy costs of each option. The expected energy costs are then: $E\left[C_{j} \mid \mathcal{I}\left(e_{i}=E S\right)\right]=E\left[C_{j}(s) \mid D_{j}\right]$, where $s$ corresponds to the certification requirement. ${ }^{5}$ Finally, a consumer may decide to not update his ${ }^{3}$ Under these assumptions, the lifetime energy costs $\left(L C_{j}\right)$ over the lifetime of the durable are given by:

$$
L C_{j}=\sum_{t=1}^{L} \rho^{t} C_{j}=\frac{1-\rho^{L}}{1-\rho} C_{j} .
$$

${ }^{4}$ This can be interpreted as a small psychological cost to detect whether or not a product has the ES label. ${ }^{5}$ If a consumer were to know the meaning of the ES certification, he would then know that the energy costs of certified products are below a particular threshold corresponding to the ES standard. Denote this threshold by $S$. If the consumer does not collect information, his belief about the meaning of $S$ is given by a prior distribution $G$. If the consumer learns the meaning of the certification, he observes a realization $s$ from $G$. If the prior on energy costs is given by the distribution $F$, the expected energy cost for a certified product $j$ is then:

$$
E\left[C_{j}(s) \mid D_{j}=1\right]=E\left[C_{j} \mid C_{j} \leq s\right]=\frac{1}{F(s)} \int_{\underline{c}}^{s} c f(c) d c,
$$

where $\underline{c}$ is the lower bound of the support of $F$, and . Similarly, the expected energy costs for a non-certified product $j^{\prime}$ is: Similarly, the expected energy costs for non-certified models are:

$$
E\left[C_{j^{\prime}}(s) \mid D_{j}=0\right]=E\left[C_{j^{\prime}} \mid C_{j^{\prime}}>s\right]=\frac{1}{1-F(s)} \int_{s}^{\bar{c}} c f(c) d c,
$$

where $\bar{c}$ is the higher bound of the support of $F$. 
priors and remain uncertain about energy costs, the meaning of the certification, and whether a product is certified or not (noted $e=U$ ). In this case, prior beliefs are uninformative, i.e., all options in the choice set have the same expected energy cost ex ante: $E\left[C_{j} \mid \mathcal{I}\left(e_{i}=U\right)\right]=\bar{C}$. In a discrete choice framework, it is as if the consumer dismisses energy costs altogether.

Prior to making a purchase, the consumer's effort to collect and process information is given by the following optimization problem:

$$
\max _{e=\{U, E S, I\}}-\mathcal{K}_{i}(e)+E_{\epsilon, D, S, \mathcal{C}}\left[\max _{j}\left\{U_{i j}\left(\delta_{j}, P_{j}, C_{j}(S), D_{j}, \epsilon_{i j}\right)\right\} \mid \mathcal{I}(e)\right] .
$$

When consumers are heterogeneous with respect to the costs of collecting and processing energy information, a fraction of the population will rely on energy costs, another on the ES certification, and others will dismiss the energy efficiency attribute.

In this framework, the certification influences consumers via three mechanisms. First, it can be used as a heuristic to compare products in a binary manner along the energy dimension, and thus partly informs about energy costs. In particular, if consumers rely on ES, instead of an accurate forecast of energy cost, they would value certified products more based on their expected energy savings: $E\left[C_{j}(s) \mid D_{j}=1\right]-E\left[C_{j^{\prime}}(s) \mid D_{j}=0\right]$. According to this mechanism, the certification thus brings welfare gains because it allows consumers to economize on information costs while still bringing some information about energy efficiency. ${ }^{6}$

A second mechanism is the effect of the label itself. That is, consumers might value certified products beyond purely their expected energy savings, and value the exact same appliance with and without the label differently. There are a number of reasons that can explain why the label might have such effect. ES products are often advertised as being environmentally friendly. Consumers might thus derive warm glow to purchase certified products, respond to social norms, or experience social prestige. Under this interpretation, the label impacts how consumers experience the product, and provides a positive utility shock. It is also possible that consumers correlate certified products with better quality, and are subject to what marketeers refer to the halo effect (Boatwright, Kalra,

${ }^{6}$ Consumers at the source of the welfare gains are the ones that would not consider energy efficiency if the certification were not in effect, but rely on the ENERGY STAR label when it is present. Note that a consumer should always choose to be fully informed if there are no extra costs to doing so, i.e., a consumer is better off with more information. A formal proof of this argument can be found in Appendix A. 
and Zhang 2008). In this case, the certification provides an illusion of higher quality, and biases consumers. Empirically, these explanations are hard to disentangle, but they are important to recognize as they have different welfare implications.

The third mechanism is simply the effect of rebates, which provide an explicit financial motivation to adopt ES products.

\section{Data and Preliminary Evidence}

The primary data used for the estimation consist of all transactions made at a large US appliance retailer during the period 2007-2011 where a full-size refrigerator was bought. The retailer offers a large selection of appliance models, and has at least one brick-and-mortar store in each US state in addition to a national online store. For each transaction, I observe the date, the model of the refrigerator, attributes, the suggested retail price, the promotional price, the wholesale price, the taxes paid, and the zipcode of the store where the transaction was made. For a large subset of transactions, I also observe consumer demographics, such as household size, income, education, homeownership, housing type, political orientation, and age of the head of the household. This demographic information is transaction specific.

The estimation focuses on refrigerators for three reasons. First, during this period, there were two events that led to the decertification of ES refrigerators. As it is further explained below, these events provide natural experiments that identify the effect of the label. Second, refrigerators are one of the few energy intensive durables for which utilization behavior has little impact on energy consumption. Operating costs can then be estimated accurately using engineering information and electricity prices. When utilization is unobserved, this creates a measurement error problem (Allcott and Wozny 2012), and can be at the source of a selection bias (Bento, Li and Roth 2012). In the present application, I can credibly rule out utilization as a source of unobserved heterogeneity, which has important implications on how to interpret the results. Finally, a third reason is that this market is representative of other appliance markets in terms of market structure and public policies it is subject to. The structural demand parameters can then be applied to a broader context. 
The construction of the key variables used in the estimation, and their main sources of variation are discussed next.

\subsection{ENERGY STAR Certification}

When a new certification requirement comes into effect, the EPA requires that manufacturers and retailers remove the ES label on certified products that do not meet the more stringent requirement. For products that display the ES logo on the EnergyGuide label, firms are also required to clearly identify that these products are decertified by masking the logo. Using data that cover the period before and after the revision in the standard, it is then possible to observe the same refrigerator model being sold at the same store, with and without the ES label. I can thus exploit this variation in labeling to identify how consumers value the ES label, while controlling for all other product attributes.

The last revision of the ES certification requirement for full-size refrigerators came into effect on April 28, 2008, and was announced exactly one year in advance by the EPA. Prior this revision, ES refrigerators had to consume at least $15 \%$ less electricity than the minimum energy efficiency standard; the revision set the stringency at $20 \%$.

For the year 2008, there were 2,524 refrigerator models available in the whole US market and 1,278 models lost their certification (Table 1). In the sample, there are 1,483 models for that year, with 674 models that were decertified. The large number of decertified models provides good power for identification, and more importantly covers all product classes. This decertification event thus allows us to elicit preferences for all segments of the population, but it brings two challenges.

First, manufacturers and retailers adjust to the revision in certification by introducing new models, and removing decertified models. This is illustrated on Figure 2, which plots the location of all the models offered for particular types of full-size refrigerators, with respect to the minimum and ES standards. The two standards are depicted by the straight lines as a function of the refrigerator size. Each dot represents a refrigerator model offered in a given year. There are two important stylized facts. First, there is strong bunching at the standards. Firms thus believe that consumers value the certification, and make product line decisions accordingly. Second, firms can adjust their product lines quickly. In the same year that the revision was announced, models 
just meeting the new certification entered the market. Following the revision, a large number of decertified models also exited the market.

If left unaccounted for, product exit would confound the effect of the change in labelling. To control for the effects of product entry and exit, I construct an unbalanced panel of refrigerator models offered on the market. In particular, for each refrigerator model, I identify the first and last month for which a model was sold at least once in a specific store. I assume that consumers shopping at this store between these two months could purchase this particular refrigerator model. ${ }^{7}$ Under these assumptions, the choice set imputed for each consumer consists of refrigerator models that were physically present in the store at the time of purchase.

The second challenge in using this large decertification event is that I do not observe the exact date that the ES label was removed or masked on each product. Although, the retailer's policy is to coordinate the change in labeling across all stores, and to implement the change close to the date mandated by the EPA, I cannot ensure that all store managers complied with the policy at an exact date. The estimation is performed under the assumption that all refrigerators that were decertified in 2008 lost their ES label on the last week of April 2008.

As a robustness test, I exploit a second decertification event that overcomes these issues. In January 2010, the EPA announced that 21 refrigerator models were subject to an incorrect testing procedure, which resulted in the underestimation of their electricity consumption. The revised test confirmed that these models did not meet the certification requirement, and should be decertified. The sample contains 14 of these models. Unlike the 2008 revision, this event came as a surprise for manufacturers and retailers. The EPA also mandated to print new EnergyGuide labels printed, and to diligently remove all references to ES after the public announcement on January 20, 2010. This event is thus appealing because it provides a sharp discontinuity in labelling, and rules out the effect of anticipation by the firms. One caveat is that the prices of these decertified models are higher that the average price (Table 1). Therefore, if different consumers sort into product classes

\footnotetext{
${ }_{7}$ Excluding the first and last month of the panel is a conservative assumption. This ensures that months were a stockout happened at the end or beginning of the month are discarded. Note that using store specific choice sets is also a conservative assumption given that the retailer can deliver appliances available at nearby stores.
} 
with expensive models, the behavioral response to this event might not be representative of the whole market.

\subsection{Prices}

The retailer implements promotions primarily at the national level due to a national price policy. Each refrigerator model is subject to large and frequent variations in prices. This high frequency temporal variation in retail prices is exploited to identify consumers' sensitivity to prices. Prices are imputed from the transaction level data. Weekly and store-specific price time series are constructed for each model, and the average tax rate is computed for each store and trimester.

Figure 3 plots the percentage change of average weekly prices relative to the suggested manufacturer retail price (a measure of promotion) together with the percentage change in weekly sales relative to average weekly sales for each refrigerator model in the sample. Figure 3 suggests that most of the promotions consist of price reductions between $5 \%$ and $25 \%$, and that correlation between sales and prices is negative and relatively large. The figure also suggests a change in the pricing strategy over time. In 2008, promotions tend to be more idiosyncratic, while in 2010 promotions are clustered at rounded percentages $(5 \%, 10 \%, 15 \%$, and $20 \%)$. The average duration of a promotion also increases from 2008 to 2010, from 1.4 week to 3.1 week (Table 1 ).

Figure 4 shows the weekly average normalized price for different classes of refrigerators. ${ }^{8}$ Around the time of the revision in April 2008, there is no significant change in prices for decertified models relative to models that were never certified, or met the more stringent requirement (i.e., models that were certified before and after April 2008). Post-decertification, prices of decertified models dip below other models by about $1 \%$ to $2 \%$, but otherwise follows a similar trend. For 2010 , the story is different. The price of decertified models drop sharply just after the announcement by as much of $15 \%$.

\footnotetext{
${ }^{8}$ The weekly average normalized price for different classes of refrigerators is computed as follows. First, the normalized price for each refrigerator model is obtained by taking the weekly retail price divided by its average weekly price. The average normalized price and standard errors in each efficiency class are then computed by fitting a cubic spline on normalized prices.
} 


\subsection{Electricity Prices}

The electricity cost of each refrigerator model is the yearly electricity consumption reported by the manufacturer multiplied by the average electricity price of the region where each household lives. $^{9}$ I assume that consumers form time-unvarying expectations about electricity prices using the current local average price. The time-unvarying assumption is consistent with recent evidence in the car market suggesting that consumers' best forecasts of future gasoline prices are simply the current prices (Anderson et al. 2011). Note also that electricity prices tend to vary much less over time than gasoline prices. For instance, between 2008 and 2010, the national average electricity price remained virtually unchanged (Table 1). Whether consumers respond to marginal or average electricity prices, and the appropriate level of spatial aggregation to compute average electricity prices is open to discussions. Ito (2012) shows that consumers respond to variations in average electricity prices within California, which suggests that fairly local average electricity prices is the most appropriate measure. Most online tools provides by the US EPA and retailers to estimate energy costs and savings associated with ES, however, rely on a state average. In the estimation, I compute average electricity prices using two different levels of aggregation, namely at the state and county level.

Average electricity prices are computed using the EIA-861 form of the Energy Information Administration (EIA 2008), which provides total revenue and sales to residential consumers for each utility operating in the US. Further assumptions and methodology to construct the average electricity prices are described in Appendix B.

The main source of identification of the coefficient on electricity costs comes from the fact that I observe the same refrigerator models being sold at stores located in different electric utility territories. This allows me to control for product and region fixed effects and use cross-sectional variation in average electricity prices across regions to identify the sensitivity to electricity prices.

${ }^{9} \mathrm{I}$ do not observe the zipcode of each household, but the zipcode of the store where each transaction was made. Each household's location is imputed from the zipcode where the purchase was made. 


\subsection{Rebates}

In the US, several electric utilities offer rebate programs to encourage the adoption of energy efficient appliances. These rebate programs are all similar in nature. Consumers claim the rebates by filling out a form that must be submitted by mail or online. The purchased refrigerator must meet a given energy efficiency criterion, which for most programs consists of the ES certification. A complete description of these programs is available in the database of state incentives for renewable and efficiency (IREC 2011). The number of active rebate programs and the amount offered by each program vary over time. In 2008, 87 utilities offered a rebate program for ES refrigerators, and this number increased to 133 in 2010 (Table 1).

In addition to utility rebate programs, state governments also offered financial incentives for ES appliances during the sample period. In 2010, as part of the stimulus effort, the federal government allocated funds to all US states and territories to establish temporary rebate programs to encourage the adoption of energy efficient products. Each state had sovereignty over the design of its rebate program, which led to important variation in the rebate amount across regions and time. During the 2010-2011 period, 44 states offered rebates for refrigerators. The average rebate amount was $\$ 128$, and varied from $\$ 50$ to $\$ 600$. Some programs lasted for only one day (e.g., IL and TX); the longest running program was in Alaska and lasted 639 days (Aldy and Houde 2013).

In the estimation, the rebate amount offered to each consumer is the average rebate amount in each county, which includes the utility and state rebates, when both are available. Utility rebates vary across county and years, while state rebates have weekly variation.

\section{The Average Consumer}

The goal of this section is to characterize the preferences of the average consumer in the US refrigerator market, and discuss the sources of variation used for identification.

The empirical strategy relies on a simple discrete choice model. Consumer $i$ living in region $r$ at time $t$ derives utility $U_{i j r t}$ from purchasing refrigerator model $j$ :

$$
U_{i j r t}=\tau D_{j t}-\eta P_{j r t}+\psi R_{r t} \times D_{j t}-\theta C_{j r t}+\delta_{j}+\epsilon_{i j r t}
$$


where $D_{j t}$ is a dummy variable that takes the value one if product $j$ is certified at time $t$ and zero otherwise. The variable $C_{j r t}$ is the annual electricity cost of product $j$ sold in region $r$. $P_{j r t}$ is the retail price, which includes all the local sales taxes, and $R_{r t}$ is the rebate amount offered in region $r$. The variables $\gamma_{j}$, and $\epsilon_{i j r t}$ denote respectively the product fixed effects, and the idiosyncratic taste parameters.

The idiosyncratic taste parameters are i.i.d. and Type I extreme value distributed, which yields closed-form expressions for the choice probabilities. The choice probabilities do not include an outside option (no purchase or purchase at other stores) because the policy analysis focuses on how energy information influences which product to purchase, not the timing of the decision. The model is estimated by maximum likelihood, where the likelihood is constructed with the choice probabilities of a large sub-sample of consumers. The sub-sample is taken from the transactions that contain demographic information. I also only consider transactions made by homeowners living in single family housing units that bought no more than one refrigerator in any given year. This restricted set of transactions is then likely to correspond to households that have to pay for their electricity bills. The sample thus rules out heterogeneity in the sensitivity to energy costs due to the split incentive problem (Blumstein et al. 1980), i.e., the fact that some consumers of energy-intensive durables do not pay for energy costs.

For the estimation, I treat the two decertification events distinctly. Moreover, because the rebate programs offered as part of the stimulus effort are in nature different from the programs offered by utilities, rebate amounts offered in 2010-2011 may have a different effect than rebates offered in prior years. The estimation is therefore carried on two separate sub-samples. The first sub-sample is taken from transactions close to the 2008 revision. Namely, only transactions from January 2008 to December 2008 are considered. ${ }^{10}$ An additional rationale to consider a restricted sample centered around April 2008 is to control for product exit. The second sub-sample is taken from all transactions made between January 2009 and December 2011. This covers the second decertification event and a period with more variation in rebates.

\footnotetext{
${ }^{10}$ Transactions for the whole month of September 2008 and prior to January 2008 do not include demographic information. They are then excluded from the sample for the structural estimation. Data for the year 2007 are used for robustness tests presented in the Online Appendix C.
} 


\subsection{Results}

Table 2 presents the estimates obtained with various specifications of the conditional logit. For all models, robust standard errors clustered at the store level are reported. The first three models are estimated using the sub-sample covering the year 2008. Model 1 is the simplest and only controls for product fixed effects. The coefficient on price is negative, relatively large, and significant. The own-price elasticity evaluated at the mean price $(\$ 1300)$ is -5.47 . This is large, but not surprising. Each refrigerator model has several close substitutes, and manufacturers and retailers offer generous promotions. Consumers can then easily substitute across models to take advantage of the promotions.

The effect of the ES label is positive and statistically significant. This translates into a willingness to pay for the label of $\$ 19$, or about $1.5 \%$ of the purchase price, on average.

The coefficient on electricity costs is negative and significant. This suggests that consumers do respond to information about electricity costs, on average. Assuming a lifetime of 18 years, the implicit discount rate is $62 \%$. This is on par with previous estimates for refrigerators that range from $35 \%$ to more than $60 \%$ (Meier and Whittier 1983). To put these numbers in perspective, in its latest cost-benefit analysis of minimum energy efficiency standards for refrigerators, the Department of Energy (DOE) used a product lifetime of 19 years, and discount rates of 3\% and 7\% (DOE 2011).

The impact of ES rebates is positive, small, and not statistically significant. As explained earlier, the coefficient on rebates should be interpreted as the marginal utility of income multiplied by the probability that a consumer takes advantage of the rebate. For the present estimates of $\eta$ and $\psi$, the implied probability of taking a rebate is below $1.0 \%$. The fact that the sub-sample covers the year 2008 implies that only cross-sectional variation in utility rebates is exploited. This limited

source of variation combined with measurement error associated with using average rebate at the county level may lead to an attenuation bias.

\subsection{Other Specifications}

Weekly variation in prices is exploited to identify the price coefficient. It can be argued that this variation is in part exogenous to demand shocks due to some institutional details of the appliance 
market. In this market, manufacturers set high MSRPs, and let retailers offer promotions. To comply with antitrust laws, retailers, however, do not offer products in constant discount, and cycle promotions across similar products. This pricing strategy provides idiosyncratic variation to identify the coefficient on prices. At specific time of the year, the retailer, however, often offer generous promotions for specific brands. Model 2 thus includes brand-week fixed effects to account for marketing efforts correlated with promotions. This has few impact on the coefficient on prices, and other coefficients as well, suggesting that the marketing effects are not a major source of bias.

The construction of the electricity operating costs relies on the assumptions that consumers do not forecast future electricity prices, and use local average prices. The lack of variation in electricity prices over time makes the first assumption uncontroversial. The second assumption may imply a degree of sophistication that not all consumers might have. Measurement error in electricity prices is therefore a concern. In the car market, Allcott and Wozny (2012) shows that measurement error in car operating costs is an important source of bias. An important difference in the present context is that the source of measurement error is not due to the unobserved utilization decision, but due to not knowing which electricity price consumers rely on when making decision. Model 3 reports results where the average state electricity price is used, instead of a county average. The magnitude of the coefficient on electricity costs increases (in absolute value), which suggests that measurement error does have an effect. In this specification, the implicit discount rate is $32 \%$, about twice smaller than in the previous specifications. Using county average electricity prices thus provides a conservative estimate of the average valuation of energy efficiency.

Because variation in electricity prices is primarily cross-sectional, a concern is that consumers living in regions subject to higher electricity prices are systematically different than others. The Online Appendix C contains additional specifications to control for region specific unobservables. Count models that include brand-week fixed effects, product fixed effects, and store fixed effects are presented. For all specifications, the coefficient on electricity prices remain negative and significant.

Model 4 is a conditional logit with product fixed effects estimated on data covering the period 2009-2011. This provides an alternative estimate of the effect of the ES label exploiting the 2010 decertification event. As discussed before, this decertification was unexpected by firms, ruling out the possible confounding effect of product entry and exit associated with the 2008 revision. The 
coefficient for the ES label is now more than twice larger than the coefficient obtained for the 2008 revision. The larger estimate can be explained in part by the fact the decertified models were expensive, and thus captures preferences of affluent households that might have a high willingness to pay for certified products. This previews the results of the next section, which show that the willingness to pay for ES increases with income. Model 5 is similar to Model 4, except that it uses only four weeks of data following the announcement on January 20, 2010. The goal of this specification is to show that even with a more conservative criterion to rule out the effect of firms' product line and inventory decisions, the coefficient on ES is still large. However, the estimate is smaller than in Model 4, and imprecisely estimated. This reassures that the change in labeling does capture demand preferences, and the label effect is not entirely confounded by firms' decisions.

Finally, note that for Models 4 and 5, the coefficient on rebate is positive, but still economically small, and only marginally significant (Model 5). The implied probability of taking advantage of a rebate varies between $9 \%$ and $14 \%$. These results are consistent with the findings of Aldy and Houde (2013), which suggest that most consumers that took advantage of rebates in 2010 would have purchased an ES appliance even in the absence of a rebate program.

\subsection{Interaction with Demographics}

I now let the demand preferences vary as a function of demographics. Table 3 first presents the estimates from a conditional logit estimated for three different income groups. I distinguish between households with income of less than $\$ 50,000$, households with income between $\$ 50,000$ and $\$ 100,000$, and households with income of more than $\$ 100,000$. As expected, lower income households have a larger coefficient on prices, which implies that the marginal utility of income is decreasing with income. The willingness to pay for the ES label is increasing with income, but the implicit discount rate is decreasing. Everything else being equal, lower income households respond less to the certification and electricity costs.

Table 3 also presents the estimates from a conditional logit estimated for the three different income groups where the ES dummy is interacted with demographics. Doing so, the coefficient on electricity costs remains virtually unchanged. This suggests that region-specific preferences for energy efficiency are not an important source of bias for the coefficient on electricity costs. It would 
be particularly problematic if, for instance, consumers living in high electricity prices regions also tended to be greener and, therefore, valued ES more. In that case, high rates of adoption of ES products in these regions would be confounded with a response to electricity prices. Interacting the ES dummy with demographic information (income, education, political orientation, age of the head of the household, and family size) provides a simple way to show that a positive correlation in the preferences for the certification and electricity costs does not mechanically drive the behavioral response to electricity costs.

In Table 4, both the coefficients on the ES dummy and electricity costs are interacted with demographics. First note that within each income group, income is still an important source of heterogeneity ${ }^{11}$ for the ES coefficient, except for the highest income group. Within the low and medium income groups, the coefficient on ES increases with income. This suggests that the willingness to pay for ES increases steadily with income until it reaches a certain threshold. The coefficient on electricity costs increases with income within the low and medium income groups. Here, a larger and positive coefficient implies that consumers value future electricity costs less (i.e., higher implicit discount rate). For these two income groups, there is then an inverse correlation between the willingness to pay for the ES label and lower electricity costs.

The effect of education varies between income groups. For the two highest income groups, households where the head has a graduate degree tend to respond more to electricity costs relative to less educated households. On the other hand, these households do not value the ES label much more. For the lowest income group, this is the inverse pattern. It thus appears that more affluent and educated households might be sophisticated enough to consider electricity costs, and by doing so they do not see extra value in the ES label.

The most important source of heterogeneity for the coefficient on electricity costs is, however, the age of the head of the household. Older households respond more to electricity costs, and this holds across the three income groups. The coefficient on ES has no clear correlation with age, and the effects are marginally significant.

\footnotetext{
${ }^{11}$ Income is measured with a categorical variable taking nine values. Each sub-sample corresponding to a particular income group contains three income groups.
} 
The size of the household matters, especially for the first two income groups. Larger families value ES more, but respond less to electricity costs.

Finally, political orientation impacts mostly preferences for ES. Perhaps surprisingly, relative to Republicans, households registered as Democrats or other political parties (including non-registered households) have a lower willingness to pay for the label.

The Online Appendix C presents an additional model where the coefficient on prices is also interacted with demographic information. Under this specification, the patterns discussed above still hold.

\subsection{Discussion}

The aforementioned estimates suggest that both the ES certification and information about electricity costs impact consumers, on average. The sign and the magnitude of the coefficients for the ES label and electricity costs are robust to several specifications. Measurement error in average electricity prices has however a relatively large impact on the coefficient on electricity costs.

Overall, consumers, at least some, appear to rely on different pieces of energy information when purchasing an appliance.

Interactions with demographics information yield interesting heterogeneity patterns. The most important finding is that the coefficients on ES and electricity costs are inversely correlated for most demographic variables. This implies that classes of consumers that value ES highly tend to respond less to electricity costs, and vice versa. Richer households of a smaller size, where the head is older and educated respond more to electricity costs. This suggests that these households might be the most sophisticated-enough to rely on the EnergyGuide and more detailed energy information. The structural model, presented next, explicitly tests this hypothesis, and yields results consistent with these patterns.

\section{Estimation: Information Acquisition Model}

To obtain an econometric specification of the information acquisition model, I maintain the assumption that the idiosyncratic taste parameters $(\epsilon)$ are extreme value distributed. In addition, I 
assume that the information acquisition costs have an unobservable idiosyncratic component, $\nu_{i e}$, that is also Type I extreme value distributed. For a level of effort, $e$, the cost for consumer $i$ is given by:

$$
\mathcal{K}_{i}(e)=K^{e}+\beta^{e} X_{i}+\nu_{i e},
$$

where $X_{i}$ is a vector of demographics, and the constant $K^{e}$ and the vector $\beta^{e}$ are coefficients to be estimated.

The choice model takes the following general form:

$$
Q_{\text {irt }}(j)=\sum_{e=\{U, E S, I\}} H_{\text {irt }}(e) P_{\text {irt }}^{e}(j),
$$

where $H_{i r t}(e)$ are the effort choice probabilities, and $P_{i r t}^{e}(j)$ are the product choice probabilities conditional on $e$. The alternative-specific utilities, $U_{i j r t}$, that enter $P_{i r t}^{e}(j)$ for each level of effort are:

$$
\begin{array}{ll}
\mathrm{e}=\mathrm{I}: & U_{i j r t}^{I}=-\eta P_{j r t}+\psi R_{r t} \times D_{j t}+\tau^{I} D_{j t}-\theta C_{j r}+\delta_{j}+\epsilon_{i j r t}^{I} \\
\mathrm{e}=\mathrm{ES}: & U_{i j r t}^{E S}=-\eta P_{j r t}+\psi R_{r t} \times D_{j t}+\tau^{E S} D_{j t}-\theta E S A V I N G S_{r t} \times D_{j t}+\delta_{j}+\epsilon_{i j r t}^{E S} \\
\mathrm{e}=\mathrm{U}: & U_{i j r t}^{U}=-\eta P_{j r t}+\gamma_{j}+\epsilon_{i j r t}^{U} .
\end{array}
$$

When $e=I$, consumers form a perfect forecast of the operating costs for each product in the choice set by multiplying the annual electricity consumption of refrigerator $j$ and the average county electricity price in region $r$. When $e=E S$, the term $E S A V I N G S_{r t}$ is the difference between the average operating costs of ES and non-ES refrigerators, in region $r$ at time $t$. The effect of the label is included for both $e=I$ and $e=E S$, which means that consumers can value certified models beyond purely energy savings in both cases. The coefficient can, however, vary across types. The effect of rebates is also included for both $e=I$ and $e=E S$. If consumers are uninformed $(e=U)$, they will trade-off refrigerators only with respect to prices and non-energy related attributes.

The effort choice probabilities are given by:

$$
H_{i r t}(e)=\frac{\exp \left(-K^{e}-\beta^{e} X_{i}+E_{\epsilon, D, S, \mathcal{C}}\left[\max _{j}\left\{U_{i j r t}\right\} \mid \mathcal{I}(e)\right]\right)}{\sum_{k} \exp \left(-K^{k}-\beta^{k} X_{i}+E_{\epsilon, D, S, \mathcal{C}}\left[\max _{j}\left\{U_{i j r t}\right\} \mid \mathcal{I}(k)\right]\right)} .
$$


Evaluating the expectation in (7) has two challenges: it requires specifying consumers' beliefs about electricity costs and ES, and then integrating over a multi-dimensional integral. The latter is particularly challenging for large choice sets, as in the present application (Table 1). The former brings an identification issue given that consumers' beliefs are not observed at the moment they make a purchase decision. This implies that the information acquisition costs that enter the effort choice probabilities are not identified given that their magnitude depend on how beliefs are specified. I circumvent these two difficulties by using a flexible representation of the expectation at different levels of effort. In particular, I approximate the expectation with variables that capture the characteristics of the choice set faced by each consumer, and related to the decision to process or not energy information.

As discussed by Sallee (2013), in a rational search model consumers might be inattentive to energy efficiency if the variance in the value of other attributes is large relatively to the variance in electricity costs. The intuition is that the ex ante value of information increases with the variance in beliefs. Therefore, if consumers have limited resources to spend on processing information, they should allocate attention such that learning about attributes has the highest expected returns. With this intuition in mind, the effort choice probabilities are specified as follows:

$$
H_{\text {irt }}(e)=\frac{e^{V_{i r t}(e)}}{\sum_{k} e^{V_{i r t}(k)}},
$$

where

$$
\begin{aligned}
V_{\text {irt }}(e=I)= & -K^{I}-\beta^{I} X_{i}+\gamma_{1}^{I} \text { MeanElec } r+\gamma_{2}^{I} \text { VarElec }_{r t}+\gamma_{3}^{I} \text { NbModel }_{r t} \\
& +\gamma_{4}^{I} \text { VarPrice }_{r t}+\gamma_{5}^{I} \operatorname{VarFE}_{r t}, \\
V_{\text {irt }}(e=E S)= & -K^{E S}-\beta^{E S} X_{i}+\gamma_{1}^{E S} \text { MeanES } S_{r t}+\gamma_{2}^{E S} \operatorname{VarES}_{r t}+\gamma_{3}^{E S} \text { NbModels } s_{r t} \\
& +\gamma_{4}^{E S} \text { VarPrice }_{r t}+\gamma_{5}^{E S} \text { VarF } E_{r t}, \\
V_{\text {irt }}(e=U)=0 . &
\end{aligned}
$$

The variables MeanElec $r$ and VarElec $r$ are the mean and variance in electricity costs for all products offered in region $r$ at time $t$, MeanE $S_{r t}$ is the proportion of ES models offered, NbModels $s_{r t}$ is the number of models in the choice set in a given region, and VarPrice rt $_{\text {is }}$ the variance in prices. 
Finally, $\operatorname{Var} F E_{r t}$ represents the variance in quality offered in each store, which is captured by the product fixed effects.

The estimation is carried with a two-step maximum likelihood procedure. In the first step, the product fixed effects are recovered by estimating a simple conditional logit with no unobserved heterogeneity. The second step estimates the information acquisition model using the product fixed effects from the conditional logit as data. The standard errors in the second step are corrected using the approach of Murphy and Topel (1985). To capture heterogeneity with respect to income, the model is estimated separately for the three different income groups.

\subsection{Identification}

The information acquisition model is a special case of a mixed logit with three discrete latent classes. It can also be interpreted as a sorting model, where the effort choice probabilities capture why consumers self-select to attend to a particular piece of energy information. The information acquisition costs are not identified because consumer beliefs are not specified. The goal of the estimation is to identify the share of consumers that fall in each latent class, and the behavioral parameters that enter the choice probabilities $\left(\eta, \theta, \tau^{I}, \tau^{E S}\right.$, and $\left.\psi\right)$. The sources of variation used to identify the coefficients on prices, electricity costs, rebates, and electricity costs have been discussed in Sections 4 and 5. In what follows, I discuss identification of the latent classes.

The latent classes capture unobserved heterogeneity in the valuation of energy efficiency. As it is customary in discrete choice models, events that induce specific substitution patterns identify heterogeneity. In the present application, the coarseness of the certification requirement versus the continuous nature of the information related to electricity costs each yields different substitution patterns, which allows us to classify consumers. To illustrate, consider a market with only three refrigerator models, all with the same quality, but with different levels of energy consumption. Figure 6 represents the location of each refrigerator model in the quality-energy efficiency characteristics space, before and after the revision in the ES standards, for three types of consumers. Panels (a) and (d) represent the location of the refrigerator models in the quality-energy cost characteristics space for consumers that are fully informed about energy costs. For this consumer type, products are located at a different address in the characteristics space. How market shares will vary for a 
relative change in prices will then be a function of the distance between products due to the difference in electricity costs. Note that for this consumer type, a revision in the ES standard (Panel (d)), represented by the line $s$, should not influence the substitution patterns. Panels (b) and (e) represent the location of the same models in the quality-ES characteristics space. This corresponds to a graphical representation of consumers that rely on the ES certification to account for the energy efficiency attribute. These consumers perceived ES refrigerators as perfect substitutes and the revision in the ES standard impacts this perception (Panel (e)). For this consumer type, the Independence of the Irrelevant Alternative (IIA) hypothesis should hold within the class of products that are certified (and with similar quality). Finally, for consumers that do not account for the energy efficiency attribute at all (panels (c) and (f)), all products are located at the same address in the characteristics space and are perceived as perfect substitutes. The IIA hypothesis should hold for all products with similar quality, irrespective of their location in the energy efficiency dimension.

To summarize, the existence of consumers with different degrees of sophistication with respect to the way they account for energy efficiency implies different latent substitution patterns. The discrete and binary nature of the ES certification allows us to distinguish consumers that trade off energy efficiency using the certification from consumers that use a more continuous measure, such as an estimate of electricity costs provided by EnergyGuide. Ultimately, each consumer type is identified by events that cause substitution between products. In the data, relative price changes and product entry and exit are two such types of events. They are both frequent and important. The decertification event, as illustrated above, also contributes to the identification.

\subsection{Results}

Table 5 presents the estimation results for each income group using the sub-sample for the year 2008. Comparing the estimates of the coefficient on electricity $\operatorname{costs}(\theta)$ of the information acquisition model with the conditional logit (Table 3) shows the importance of controlling for heterogeneity in consumer sophistication. While the conditional logit model suggests a large undervaluation of energy efficiency, this phenomenon has a more nuanced interpretation in the information acquisition model. For consumers that rely on electricity costs $(e=I)$, the implicit discount rate is low and on par with other investment decisions. Therefore, the a priori hypothesis that a share of consumers 
behave as if they were perfectly informed holds true. In the present framework, the existence of a so-called Energy Efficiency Gap (Jaffe and Stavins 1994) is attributable to the existence of a share of uninformed consumers that dismiss the energy efficiency attribute altogether. This share is $65 \%$, $41 \%$, and $33 \%$ for the low, medium, and high income group, respectively.

With the information acquisition model, the issue of measurement error in average electricity prices also becomes a moot point. The share of perfectly informed consumers corresponds to consumers that are sophisticated enough to use county average electricity prices in their decision. As long as this is the share of consumers that I am interested to identify for the policy analysis, county averages are the appropriate level of aggregation. If I were to use a different measure of electricity prices, such as state averages, the share of perfectly informed consumers would simply correspond to a different type of consumers.

The share of consumers that rely primarily on ES $(e=E S)$ increases with income. These consumers have a high WTP for the label itself (coefficient $\tau^{m}$ ), which ranges from $\$ 95$ to $\$ 152$. This implies that some consumers value the certification well beyond the average energy savings associated with the certification. On average, the discount value of the energy savings associated with ES are $\$ 83$ for the year $2008 .^{12}$

On the other hand, consumers that are fully informed $(e=I)$ have a low WTP for ES, and even negative for the lower income group. This suggests that the ES certification and information about electricity costs are substitute. For some consumers, the ES label is simply superfluous, but for others, it is a highly valued attribute. Whether ES is a useful heuristic from a welfare standpoint is, however, unclear. The large willingness to pay for the label itself is puzzling, and suggests that consumers might have a biased perception of the overall quality of certified products.

Relative to the conditional logit (Table 3), the coefficients on rebate increase, are positive, and become significant for the lower income groups. Again, this shows the importance of accounting for heterogeneity in sophistication. Lower income households have a higher propensity to take advantage of a rebate program, which is consistent with the idea that, relative to richer households, they may be more willing to overcome the hassle costs of claiming a rebate.

\footnotetext{
${ }^{12}$ Assuming that non-ES refrigerators consume $568 \mathrm{kWh} /$ year and ES refrigerators consume $500 \mathrm{kWH} /$ year,
} a lifetime of 18 years, and an average electricity price of $0.113 \$ / \mathrm{kWh}$ (Table 1 ). 
The coefficients that enter the latent probabilities are highly consistent with the results of the conditional logit interacted with demographics (Table 4). Again, I find that richer, but smaller households, where the head is older and has a graduate degree are more likely to rely on electricity costs. Age and education are also correlated positively with the probability of relying on ES. Republicans, relative to Democrats or households that have other political orientation, are more likely to rely on the certification. The variables that capture the choice set faced by each consumer tend to not have a significant impact. The higher the proportion of ES models offered, the more likely consumers are to rely on the certification.

\section{Alternative Estimator: Heterogeneity}

The information acquisition model introduces heterogeneity along observable and unobservable dimensions in a parsimonious, but restrictive manner. This section presents a more flexible estimator to capture unobserved heterogeneity. In particular, I recover the nonparametric joint distribution of the coefficients on the ES label $(\tau)$ and electricity $\operatorname{costs}(\theta)$ using the estimator proposed by Fox et al. (2011) (FKRB). The estimator provides one more piece of evidence that the preference parameters $\tau$ and $\theta$ are inversely correlated. It also shows that the information acquisition model captures well the main patterns of unobserved heterogeneity.

The estimator works as follows. Suppose that $\tau$ has support on the $[\underline{\tau}, \bar{\tau}]$ interval, and similarly $\theta$ has support on $[\underline{\theta}, \bar{\theta}]$. FKRB propose to take a large but finite number of grid points on the intervals, and treat each point as a random coefficient with an unknown frequency that needs to be estimated. Taking all combinations of grid points, say $M$, I can form the choice probabilities for each combination, $m$, and approximate the choice probability for each consumer $i$ by averaging over all the random coefficients:

$$
Q_{i j r t} \approx \sum_{m=1}^{M} \alpha_{m} \cdot P_{i j r t}^{m}\left(\beta^{m}\right),
$$

where $\alpha_{m}$ is the unknown frequency of the pair of random coefficients: $\beta^{m}=\left\{\tau^{m}, \theta^{m}\right\}$, and $P_{i j r t}^{m}\left(\beta^{m}\right)$ is the choice probability evaluated at $\beta^{m}$. As shown by FKRB, the fact that the dependent 
variable of the model $P_{i j r t}$ is linearly related to the parameters $\alpha_{m}$ allows us to consistently estimate $\alpha_{m}$ using inequality constrained least squares. ${ }^{13}$

For the present application, I fix $\eta, \psi$ and $\gamma_{j}$ at their MLE estimates (Model 1, Table 2), and center the support of $\tau$ and $\theta$ around the MLE estimates. ${ }^{14}$ To recover a smooth joint distribution of random parameters, I model the joint density of $\tau$ and $\theta$ as a mixture of normal basis densities instead of point masses, as suggested by FKRB. Using the simpler estimator with point masses produces qualitatively similar results. Additional details on the implementation can be found in Appendix D.

Figure 5 plots the contour map of the estimated joint density of the parameters $\theta$ and $\tau$ for different income groups. For lower income households (Figure 5(a)), two clusters are identified, one with a relatively low valuation to energy costs and ES, and a second with a low sensitivity to energy costs, but a high valuation of ES. For households in the second income group (Figure 5(b)), the distribution has a similar pattern. For higher income households (Figure 5(c)), three large clusters are identified: households with a low valuation of ES and electricity costs; a low valuation of ES, but a high valuation of electricity costs, and a high valuation of ES and low valuation of electricity costs. A fourth, but marginal cluster, where households have a high valuation of both ES and electricity costs is also detected.

Altogether, the heterogeneity patterns identified are consistent with the fact that preferences for the ES certification and a continuous measure of electricity costs are inversely correlated. Consumers that rely on a particular piece of information are less likely to rely on the other, and vice versa. Moreover, the FKRB estimator also reveals that a discrete model with few latent classes, as in the information acquisition model, is sufficient to capture the main sources of unobserved heterogeneity. It also suggests that using a mixed logit model relying on an unimodal distribution to capture unobserved heterogeneity, as it is customary in the literature, will provide a poor fit to the data.

\footnotetext{
${ }^{13}$ This estimator is thus appealing because of its computational simplicity. It is, however, prone to suffer from the curse of dimensionality, and requires some subjectivity in the choice of grid points.

${ }^{14}$ The estimator is a special case of a two-step estimator. FKRB propose a bootstrap procedure to recover the standard errors in the second step. An approach similar to Murphy and Topel (1985) can also be used to account for the fact that some parameters that enter the choice model were estimated in the first step. In the present application, the estimated joint distributions are presented graphically, without standard errors.
} 


\section{The Value of Energy Information}

This section shows how consumers, firms, and society as a whole might lose, or even gain, when some consumers rely on ES or dismiss energy efficiency altogether instead of being perfectly informed about energy costs. In particular, I quantify the opportunity costs of imperfect energy information in the US refrigerator market. This is a first step toward performing a welfare analysis of ES. A complete analysis would require to compare these costs to the economies in the costs of collecting and processing information brought by the certification. I do not quantify these economies. The concept of opportunity cost of imperfect energy information is in itself important for policy design. It provides an upper bound on the net benefits of better informing consumers in this market.

Formally, I define the opportunity cost of imperfect energy information as the difference between the welfare that would be achieved if all consumers were to make a purchase perfectly informed, versus the expected welfare that is achieved when consumers are relying on ES or dismissing energy efficiency. The structural model can readily be used to simulate these quantities. If all consumers are perfectly informed, the choice probabilities are given by: $Q_{i r t}(j)=P_{i r t}^{e=I}(j)$, and the expected welfare is:

$$
E\left[W_{i r t} \mid \mathcal{I}(e=I)\right]=\frac{1}{J} \sum_{j}^{J} P_{i r t}^{e=I}(j) \cdot\left(C S_{j}+P S_{j}-E X T_{j}\right),
$$

where $C S_{j}$ is a measure of consumer surplus associated with product $j, P S_{j}$ is the producer surplus, and $E X T_{j}$ are the externality costs. The opportunity costs of relying on ES or being uninformed are, respectively, given by:

$$
\begin{aligned}
& E\left[W_{i r t} \mid \mathcal{I}(e=I)\right]-E\left[W_{i r t} \mid \mathcal{I}(e=E S)\right]= \\
& \frac{1}{J} \sum_{j}^{J}\left(P_{i r t}^{e=I}(j)-P_{i r t}^{e=E S}(j)\right) \cdot\left(C S_{j}+P S_{j}-E X T_{j}\right), \\
& E\left[W_{i r t} \mid \mathcal{I}(e=I)\right]-E\left[W_{i r t} \mid \mathcal{I}(e=U)\right]= \\
& \frac{1}{J} \sum_{j}^{J}\left(P_{i r t}^{e=I}(j)-P_{i r t}^{e=U}(j)\right) \cdot\left(C S_{j}+P S_{j}-E X T_{j}\right),
\end{aligned}
$$

where $P_{i r t}^{e=E S}(j)$ and $P_{i r t}^{e=U}(j)$ correspond to the choice probabilities of each consumer type. 
Consumer Surplus. According to the information acquisition model, for consumers that do not fully process energy information, there is a discrepancy between the electricity costs they believe they would pay and the electricity costs they effectively pay. That is, the utility they experience differs from the utility they thought they would experience. This gap between decision and experience utility raises the question of what concept of utility should be used to measure consumer welfare. I propose a measure of consumer surplus based on the notion of experience utility, and make the following assumption.

Assumption 1. If $e=I$, decision utility equals experience utility.

Assumption 1 simply says that under perfect information consumers experience what they believed they would experience. Under this assumption, the consumer surplus is the observed component of experience utility corresponding to the perfectly informed consumers:

$$
C S_{i j r t}=\frac{1}{\eta}\left(\gamma_{j}+\tau D_{j t}-\eta P_{j r t}+\psi R_{r t} \times D_{j t}-\theta C_{j r}\right) .
$$

In particular, I have divided by the marginal utility of income to convert utils into dollars. ${ }^{15}$

Whether the effect of the ES label is truly experienced, and whether $\tau^{I}$ or $\tau^{E S}$ should be used can be debated. A key insight from the empirical analysis is that consumers that rely on ES value certified products well beyond purely energy savings. Whether this high willingness to pay for the label itself reflects a behavioral bias or corresponds to preferences has important welfare implications. If consumers are subject to a bias akin of the halo effect, i.e., wrongfully believe that certified products are of higher quality simply because of the label, they will pay too much for certified products. Under this interpretation, the label effect might then reduce welfare. Empirically, $\tau^{I}$ tend to be close to zero, and $\tau^{E S}$ to be large. I then propose to bound the change in consumer surplus by considering a measure that simply excludes the label effect, and a measure that includes $\tau^{E S}$.

Producer Surplus. For each refrigerator model in the sample, I observe the wholesale price. I define the producer surplus as the difference between the retail and wholesale price. This measure

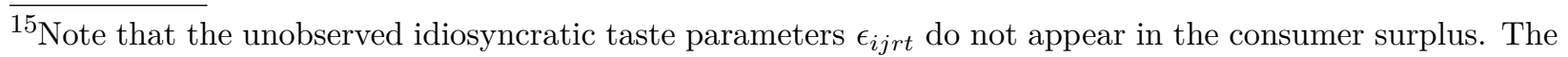
measure thus corresponds to the expected consumer surplus, because I use the fact that $E_{\epsilon}\left[\epsilon_{i j r t}\right]=0$. Also, note that (13) should be interpreted as the expected consumer surplus over the lifetime of the refrigerator. 
of producer surplus should be interpreted as a lower bound, because it excludes manufacturers' profits. $^{16}$

Externality Costs. To quantify the externality costs associated with the electricity generated to operate refrigerators, I focus on the emissions of greenhouse gases $\left(\mathrm{CO}_{2}, \mathrm{CH}_{4}, \mathrm{~N}_{2} \mathrm{O}\right)$, sulphur dioxide $\left(\mathrm{SO}_{2}\right)$, and nitrous oxide $\left(\mathrm{NO}_{x}\right)$, and use emissions factors recommended by the EPA. The externality costs associated with each scenario are the product of the corresponding average electricity consumption purchased, the emission factors, and the damage costs of electricity generation, where the average electricity consumption purchased is the average of the electricity consumption of the refrigerators sold, weighted by market shares.

The dollar damages associated with carbon dioxide correspond to the recent estimates of the social cost of carbon recommended to assess federal regulations (Greenstone, Kopits and Wolverton 2011). For sulphur dioxide and nitrous oxide, I rely on the estimates used by the Department of Energy in the cost-benefit analysis of the 2014 minimum energy efficiency standards for refrigerators (DOE 2011), and the estimates provided by Muller and Mendhelson (2012). Table 9 presents the emission factors and the damage costs. The results that I report use the high estimates.

\subsection{Results}

ENERGY STAR at 20\%. In this scenario, the stringency of the ES requirement is set at $20 \%$ below the federal minimum energy efficiency standard. ${ }^{17}$ The demand model is simulated with the estimates of Table 5 using a random sample of 2,000 households. The electricity prices, and rebates faced by each household are the same as in the demand estimation. The products on the market are all refrigerator models observed in the year 2008 that were included in the demand estimation. Figure 7(a) shows the distribution of the products with respect to energy efficiency. Products bunch at the minimum and ES standards. There is also a large number of products that meet the previous certification requirement (15\% more efficient than the minimum). The price of each model is the average price observed in the post-revision period (May-December 2008).

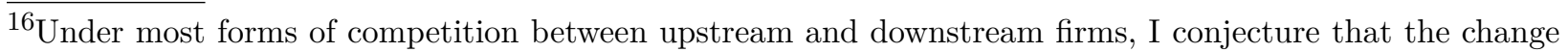
in profits between manufacturers and retailers are of the same sign (Bresnahan and Reiss 1985).

${ }^{17} \mathrm{~A}$ product can be certified if it consumes at least $20 \%$ less electricity than a similar model that just meet the minimum standard.
} 
Table 6 presents the estimates of the opportunity costs with respect to the various metrics that enter welfare. The first column compares the outcomes obtained under the information acquisition model to a model where all consumers make a purchase decision perfectly informed. These estimates correspond to the opportunity costs of imperfect energy information under the current labeling policies. The opportunity costs of being completely uninformed or relying solely on ES are presented in the second and third column, respectively.

Focusing on the measure of consumer surplus that includes the label effect $\left(\tau^{E S}\right)$, consumers lose $\$ 19$, on average, under the information acquisition model. This estimate can be interpreted as an upper bound on the additional costs of collecting and processing energy information that consumers that rely on ES or dismiss energy efficiency should be ready to invest to become perfectly informed. Put simply, this estimates suggest that consumers are willing to forgo $\$ 19$, on average, to not have to deal with energy information. The opportunity cost of being completely uninformed about energy efficiency is larger: $\$ 28$ on average for all income groups, and is the largest for the lowest income households (\$33). If all consumers were to rely on ES, the opportunity costs would be $\$ 21$. This is an improvement relative to the case where all consumers are uninformed. This conclusion, however, only holds if the label effect is included in the consumer surplus. If excluded, the opportunity cost of relying on ES increases to $\$ 42$, while the opportunity cost of being uninformed is only $\$ 29$. Here, although ES provides some information about energy efficiency, it still makes consumers worst-off, relative to the scenario where no information is provided. This is a counterintuitive result. This shows that by excluding the label effect from the consumer surplus, the certification is effectively acting as a bias. Ex post, consumers are then worst-off because the label led them to pay too much for certified products.

Turning to other metrics, under perfect information, consumers choose more energy efficient refrigerators, on average. The reduction in electricity consumption under ES is similar to the reduction achieved with only uninformed consumers. The certification then brings modest welfare gains from the reduction in externality costs. The fact that the certification requirement is set in relative terms and depends on other attributes, such as size, explains this result.

The size of the externality costs under the information acquisition model is $\$ 14$ per refrigerator sold. The opportunity cost of imperfect energy information measured in terms of consumer surplus 
net of the externality costs thus ranges between $\$ 34$ to $\$ 40$, depending on how the label effect is interpreted.

Firms are better off when consumers are not perfectly informed, and would gain the most if all consumers were to rely on ES. This implies that firms maintain larger markups on certified products. This estimate should, however, be interpreted with an important caveat. If all consumers were perfectly informed, firms would make different product line and pricing decisions. In the mediumterm, the impact on profits could then be different. In a related paper (Houde 2013), I show that once product line and pricing decisions are endogenized, the large willingness to pay for the ES label allows firms to charge larger markups not only on certified products, but also on non-certified products. In sum, firms appear to benefit largely from the existence of the certification both in the short and long-run.

The above results also suggest that firms' provision of energy information may not be fully compatible with the social planner's objective. Using a similar framework, Sallee (2013) shows that firms may be better off distorting the provision of other non-energy attributes so that consumers pay less attention to energy efficiency.

Overall, once I account for the change in consumer surplus, externalities, and profits, there is an opportunity cost associated with consumers not being perfectly informed that ranges from $\$ 12$ to $\$ 17$ per refrigerator sold. Assuming a market size of 9.01 million (DOE 2011), the value of perfect energy information is more than $\$ 108 \mathrm{M} /$ year for the refrigerator market alone. To put this number in perspective, the EPA and the DOE have spent $\$ 57.4 \mathrm{M} /$ year, on average, during the period 2008-2011 to run the whole ES program (US Government Accountability Office GAO), which includes more than sixty categories of products.

\subsection{Sensitivity Tests}

In the online Appendix E, several sensitivity tests are presented. The results are summarized below.

Electricity Prices, Rebates. Electricity prices and financial incentives for ES products vary widely across the US. Table 10 provides estimates of the opportunity costs for a scenario with low 
electricity prices, and no rebate. In this scenario, the average electricity price is set at $0.08 \$ / \mathrm{kWh}$ for all consumers.

As expected, lower electricity prices translate in a lower value of energy information for consumers. Consumers are simply more likely to not pay attention to energy efficiency. In this scenario, the overall opportunity cost, accounting for the change in consumer surplus, externalities, and profits is between $\$ 4$ to $\$ 8$.

Table 11 presents estimates where the electricity price is set at $0.16 \$ / \mathrm{kWh}$, and a $\$ 50$ rebate is offered to all consumers. In this scenario, the value of energy information is much larger for consumers, and the opposite for firms. On the other hand, the externality costs remain unaffected, relative to the previous scenarios. The overall opportunity cost now ranges from $\$ 21$ to $\$ 25$.

Choice Set. In constructing the choice set for each household, I use all refrigerator models present in the sample during the year 2008. As a result, the choice sets include several models that meet the previous certification requirement, but are no longer certified. As observed on Figure 7(b), these products exit the market in the long term. In equilibrium, firms try to maintain a distribution of products that either just meet the minimum standard or the ES certification. In this scenario, I modified the choice sets to reflect such an equilibrium. In particular, all models that just meet the previous requirement, i.e., that are $15 \%$ more efficient than the minimum standard, were excluded (Figure $7(\mathrm{~b}))$.

The main take away is that under this scenario, relying solely on ES has a much lower opportunity cost (Table 12). If there is close to perfect bunching at the minimum standard and ES in the product offering, the loss in accuracy incurred by trading-off energy efficiency in a binary manner becomes minimal. This explains that bunching can be sustained in equilibrium. If firms offer products that bunch at the minimum standard and ES, consumers have higher incentive to use the certification as a decision heuristic, which in turn reinforces firms' incentives to bunch. Whether these distortions are welfare improving is unclear. The coarse nature of the certification crowds out consumers' and firms' incentives to purchase and offer products that exceed the ES requirement. As a result, the certification might have the unintended consequence to reduce the provision of energy efficiency. 


\section{Conclusion}

This paper first shows that consumers, on average, respond to both the ES certification and electricity costs in the appliance purchasing decision. It then provides evidence that consumers are heterogeneous in the way they respond to different pieces of energy information. The main contribution of the paper is a structural estimator that classifies consumers in three types: consumers that rely on a continuous measure of electricity costs, consumers that rely on the ES certification, and consumers that do not pay attention to energy-related information. Identification comes from the fact that consumer types respond differently to changes in relative prices, choice sets, and decertification events; each type is thus associated with a specific substitution pattern. Empirically, the prevalence of each substitution pattern determines the share of consumers that belongs to each type.

The estimator provides several insights on how a certification that summarizes complex, but easily accessible information influences choices. In the present context, for the share of consumers that rely on an accurate measure of electricity costs, the certification appears to have no effect. On the other hand, consumers that rely on ES have a high willingness to pay for the label itself that is well beyond the value of the energy savings associated with certified products. From a welfare standpoint, the interpretation of the label effect has important implications. Further research is, however, needed to better identify the mechanisms that explain the strong effect of the ES label, and whether those mechanisms apply to other contexts.

The policy analysis shows that a consumer in the US refrigerator market loses between $\$ 19$ to $\$ 24$, on average, for not being perfectly informed about electricity costs. If all consumers were perfectly informed, choices would be more energy efficient, and the externality costs would be reduced by $\$ 14$ per refrigerator sold. Interestingly, the opportunity costs measured in terms of externality costs do not differ by a large amount whether consumers rely solely on the certification or are completely uniformed about electricity costs. Firms are better off when not all consumers are perfectly informed, and benefit the most when consumers rely on ES.

Accounting for the change in consumer surplus, externality costs, and profits, I find that the overall opportunity cost of imperfect energy information ranges from $\$ 12$ to $\$ 17$ per refrigerator 
sold. Scaling these estimates by the size of the refrigerator market, the total size of the opportunity cost is $\$ 108 \mathrm{M} /$ year, a number twice as large the annual program costs of ES.

\section{References}

Abaluck, Jason. 2011. "What Would We Eat if We Knew More: The Implications of a Large-Scale Change in Nutrition Labeling." Massachusetts Institute of Technology Working Paper.

Abaluck, Jason, and Jonathan Gruber. 2011. "Choice Inconsistencies among the Elderly: Evidence from Plan Choice in the Medicare Part D Program." The American Economic Review, 101(4): 1180-1210.

Akerlof, George A. 1970. "The Market for "Lemons": Quality Uncertainty and the Market Mechanism." The Quarterly Journal of Economics, 84(3): pp. 488-500.

Aldy, Joseph, and Sébastien Houde. 2013. "Did the Stimulus Benefit the Environment? New Evidence from Cash for Appliances." Working Paper.

Allcott, Hunt. 2011. "Consumers' Perceptions and Misperceptions of Energy Costs." American Economic Review, 101(3): 98-104.

Allcott, Hunt, and Nathan Wozny. 2012. "Gasoline Prices, Fuel Economy, and the Energy Paradox." National Bureau of Economic Research Working Paper 18583.

Anderson, Soren T, Ryan Kellogg, James M Sallee, and Richard T Curtin. 2011. "Forecasting gasoline prices using consumer surveys." American Economic Review, 101(3): 110.

Bagwell, Kyle. 2007. "Chapter 28 The Economic Analysis of Advertising." In . Vol. 3 of Handbook of Industrial Organization, , ed. M. Armstrong and R. Porter, 1701 - 1844. Elsevier.

Bento, Antonio M., Shanjun Li, and Kevin Roth. 2012. "Is there an energy paradox in fuel economy? A note on the role of consumer heterogeneity and sorting bias." Economics Letters, 115(1): $44-48$.

Berry, Steven T. 1994. "Estimating Discrete-Choice Models of Product Differentiation." The RAND Journal of Economics, 25(2): pp. 242-262. 
Blumstein, C., B. Krieg, L. Schipper, and C. York. 1980. "Overcoming Social and Institutional Barriers to Energy Conservation." Energy, 5: pp. 355-371.

Borenstein, Severin. 2010. "The Redistributional Impact of Non-Linear Electricity Pricing." Energy Institute at Haas Working Paper 204.

Bresnahan, Timothy F., and Peter C. Reiss. 1985. "Dealer and Manufacturer Margins." The RAND Journal of Economics, 16(2): pp. 253-268.

Busse, Meghan R., Christopher R. Knittel, and Florian Zettelmeyer. 2013. "Are Consumers Myopic? Evidence from New and Used Car Purchases." American Economic Review, 103(1): 220-56.

DOE. 2011. "Energy Conservation Program: Energy Conservation Standards for Residential Refrigerators, Refrigerator-Freezers, and Freezers." Federal Register, 76(179).

Dranove, David, and Ginger Zhe Jin. 2010. "Quality Disclosure and Certification: Theory and Practice." Journal of Economic Literature, 48(4): 935-63.

EIA. 2008. "Form EIA-861." Energy Information Administration http://www.eia.gov/cneaf/electricity/page/eia861.html.

Fox, Jeremy T., Kyoo Kim, Stephen P. Ryan, and Patrick Bajari. 2011. "A Simple Estimator For The Distribution Of Random Coefficients." Quantitative Economics, 2(3): 381 418.

Gabaix, Xavier, David Laibson, Guillermo Moloche, and Stephen Weinberg. 2006. "Costly Information Acquisition: Experimental Analysis of a Boundedly Rational Model." American Economic Review, 96(4): 1043-1068.

Greenstone, Michael, Elizabeth Kopits, and Ann Wolverton. 2011. "Estimating the Social Cost of Carbon for Use in U.S. Federal Rulemakings: A Summary and Interpretation." National Bureau of Economic Research, Inc NBER Working Papers 16913.

Handel, Benjamin R., and Jonathan T. Kolstad. 2013. "Health Insurance for ŞHumans Ť: Information Frictions, Plan Choice, and Consumer Welfare." National Bureau of Economic Research Working Paper 19373. 
Houde, Sébastien. 2013. "Bunching with the Stars: How Firms Respond to Environmental Certification." University of Maryland Working Paper.

Imbens, Guido W., and Joshua D. Angrist. 1994. "Identification and Estimation of Local Average Treatment Effects." Econometrica, 62(2): pp. 467-475.

IREC. 2011. "Database for State Incentives for Renewable and Efficiency." http://www.dsireusa.org/.

Ito, Koichiro. 2012. "Do Consumers Respond to Marginal or Average Price? Evidence from Nonlinear Electricity Pricing." National Bureau of Economic Research Working Paper 18533.

Jaffe, Adam B, and Robert N Stavins. 1994. "The energy-efficiency gap What does it mean?" Energy policy, 22(10): 804-810.

Klier, Thomas, and Joshua Linn. 2010. "The Price of Gasoline and New Vehicle Fuel Economy: Evidence from Monthly Sales Data." American Economic Journal: Economic Policy, 2(3): 13453.

Li, Shanjun, Christopher Timmins, and Roger H. von Haefen. 2009. "How Do Gasoline Prices Affect Fleet Fuel Economy?" American Economic Journal: Economic Policy, 1(2): pp. $113-137$.

Mason, Charles F. 2013. "The Economics of Eco-Labeling: Theory and Empirical Implications." Center for Energy and Environmental Economics Working Paper.

McCall, John J. 1965. "The Economics of Information and Optimal Stopping Rules." The Journal of Business, 38(3): pp. 300-317.

McWhinney, Marla, Andrew Fanara, Robin Clark, Craig Hershberg, Rachel Schmeltz, and Judy Roberson. 2005. "ENERGY STAR Product Specification Development Framework: Using Data and Analysis to Make Program Decisions." Energy Policy, 33(12): 1613 - 1625.

Meier, Alan K., and Jack Whittier. 1983. "Consumer Discount Rates Implied by Purchases of Energy-Efficient Refrigerators." Energy, 8(12): 957 - 962.

Muller, Nicholas Z., and Robert Mendelsohn. 2012. "Efficient Pollution Regulation: Getting the Prices Right: Corrigendum (Mortality Rate Update)." American Economic Review, 102(1). 
Newell, Richard G., and Juha Siikamäki. 2013. "Nudging Energy Efficiency Behavior, The Role of Information Labels." Resources for the Future RFF Discussion Paper 13-17.

Sallee, James M. 2013. "Rational Inattention and Energy Efficiency." National Bureau of Economic Research Working Paper 19545.

Sims, Christopher A. 2003. "Implications of Rational Inattention." Journal of Monetary Economics, 50(3): $665-690$.

Stigler, George J. 1961. "The Economics of Information." Journal of Political Economy, 69(3): pp. $213-225$.

US Government Accountability Office (GAO). 2011. "ENERGY STAR Providing Opportunities for Additional Review of EPA's Decisions Could Strengthen the Program." Report to Congressional Requesters. GAO-11-888.

Viscusi, W Kip. 1978. "A Note on "Lemons" Markets with Quality Certification." Bell Journal of Economics, 9(1): 277-279.

Ward, David O., Christopher D. Clark, Kimberly L. Jensen, Steven T. Yen, and Clifford S. Russell. 2011. "Factors influencing willingness-to-pay for the ENERGY STAR label." Energy Policy, 39(3): 1450 - 1458. 


\section{Figures}

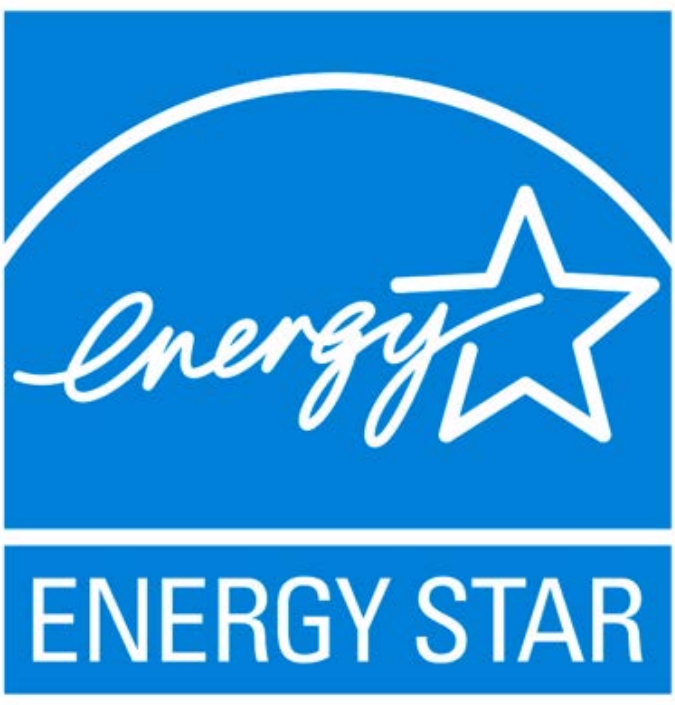

(a) ES label

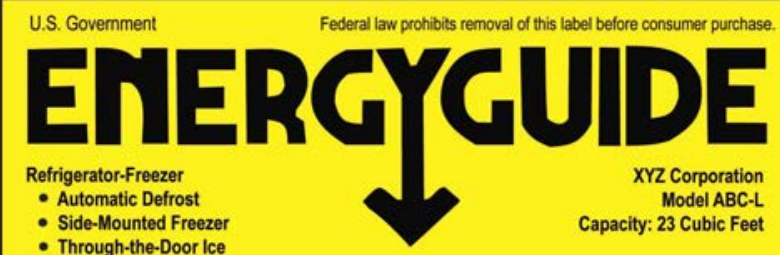

Estimated Yearly Operating Cost

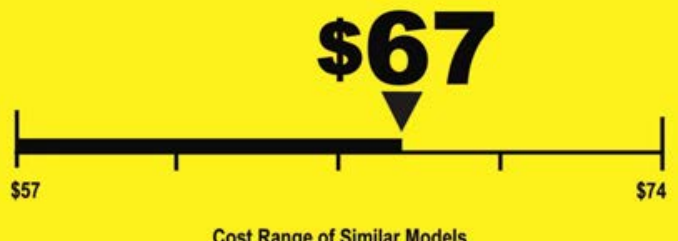

Cost Range of Similar Models

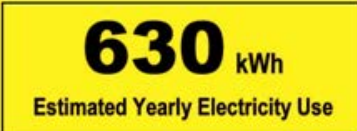

Your cost will depend on your utility rates and use.

- Cost range based only on models of similar capacity with automatic defrost,

side-mounted freezer, and through-the-door ice.

- Estimated operating cost based on a 2007 national average electricity cost of

10.65 cents per $\mathrm{kWh}$.

- For more information, visit www.ftc.govlappliances.

(b) EnergyGuide label

Figure 1. Energy Labels for the US Appliance Market 

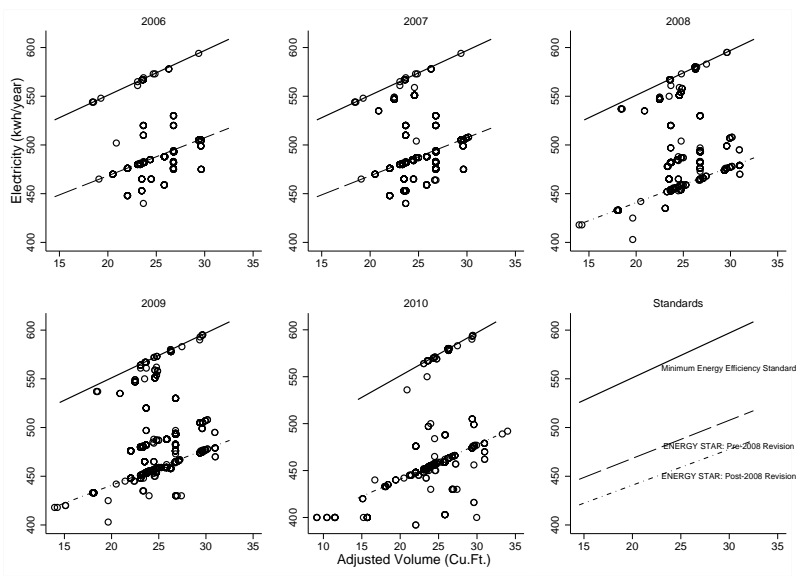

(a) Bottom-Freezer Refrigerator without Ice-Maker
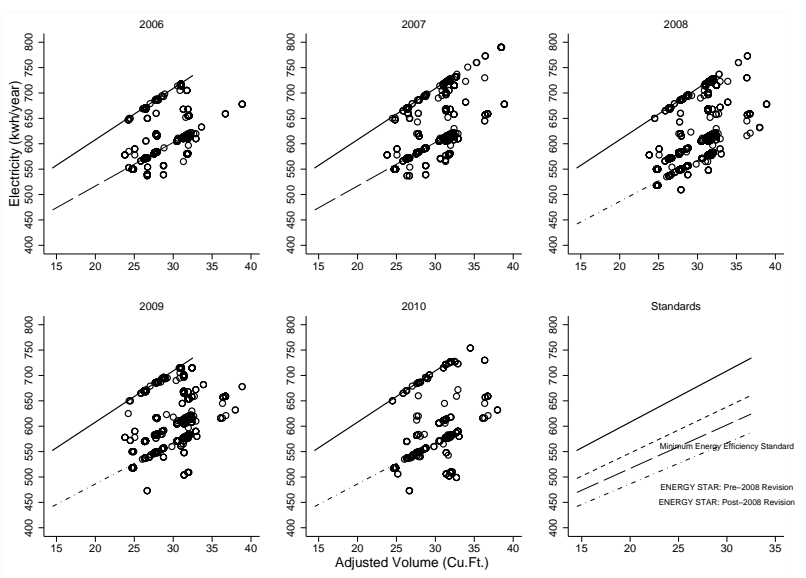

(b) Side-by-Side Refrigerator with Ice-Maker
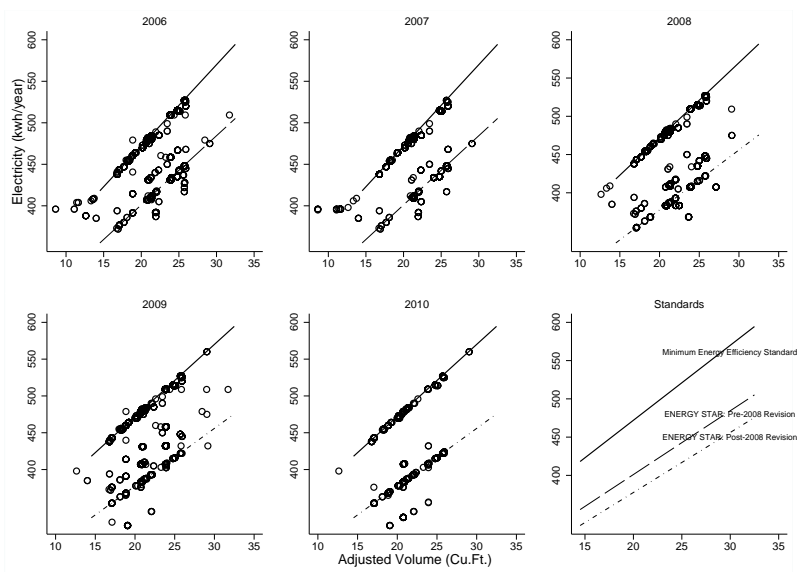

(c) Top-Freezer Refrigerator without Ice-Maker

Figure 2. Choice Set Full-Size Refrigerators: 2006-2010 

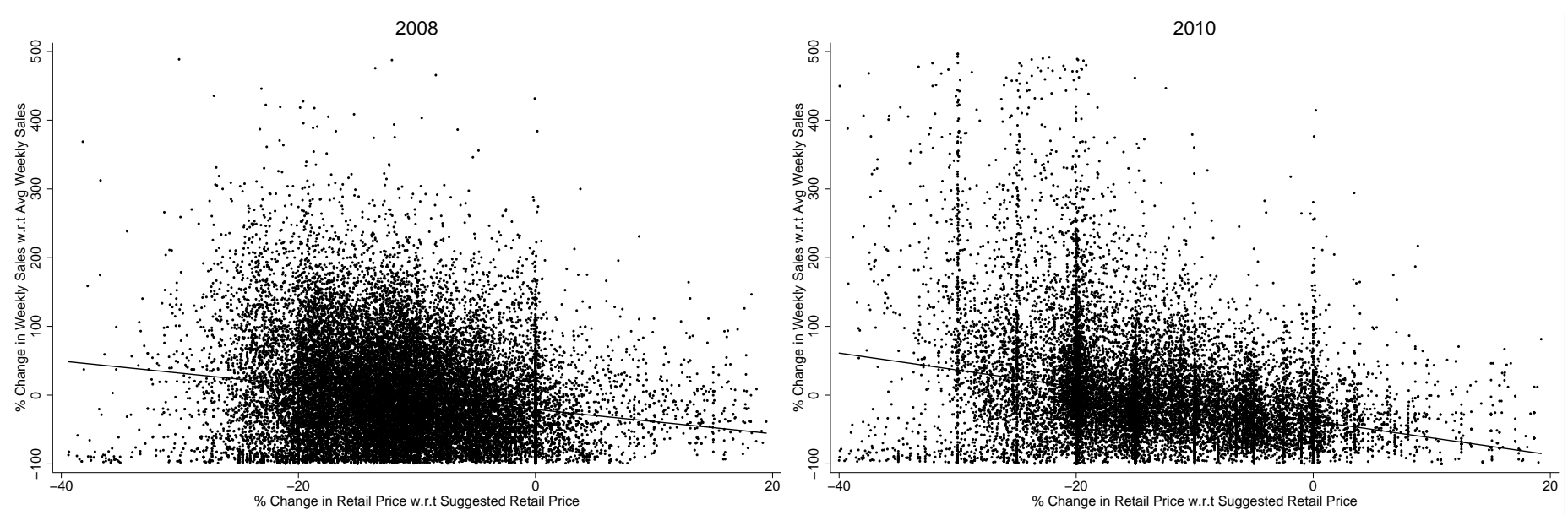

Figure 3. Correlation Between Sales and Prices
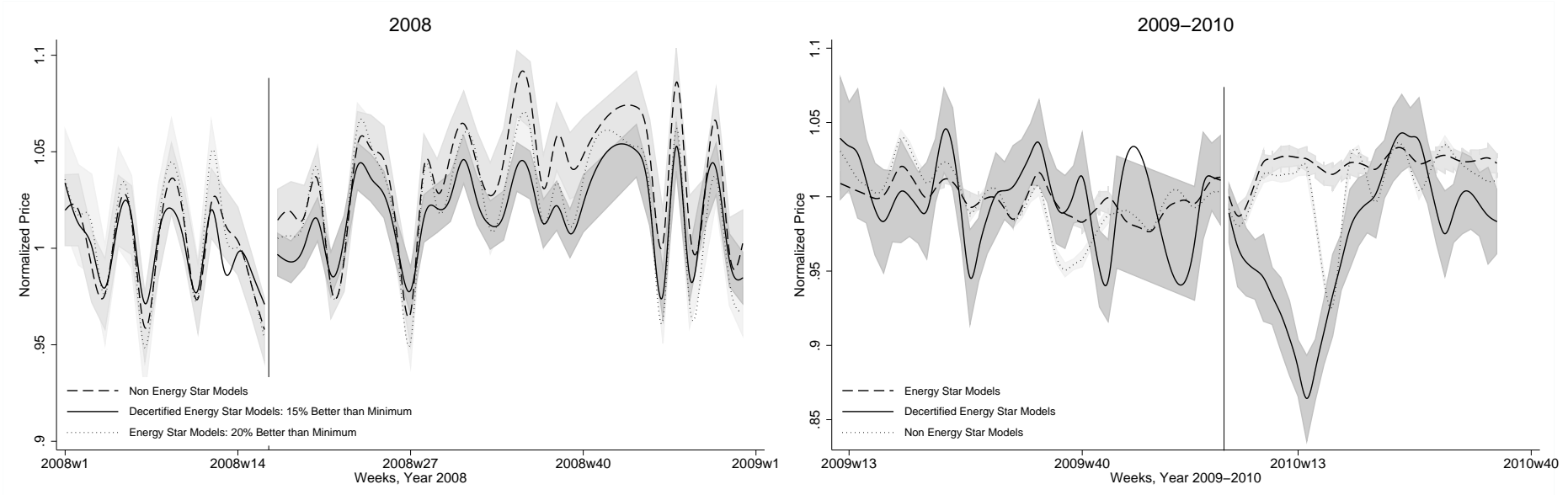

Figure 4. Normalized Prices Before and After Decertification

Each panel displays average normalized weekly prices, with $5 \%$ confidence intervals, of refrigerators that belong to different efficiency classes. The left panel shows that the price of decertified models slightly decrease after the decertification, but the change is small. The right panel shows a large, but temporary price decrease following the decertification event. 


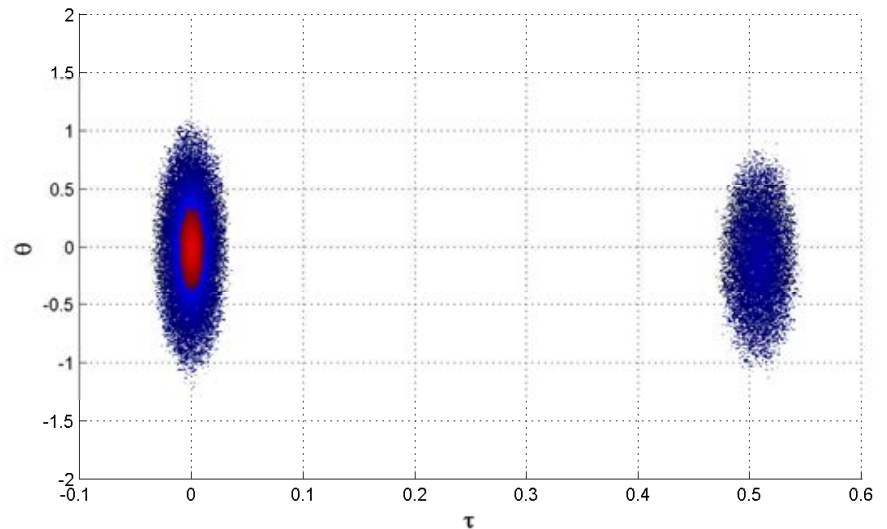

(a) Income $<\$ 50,000$

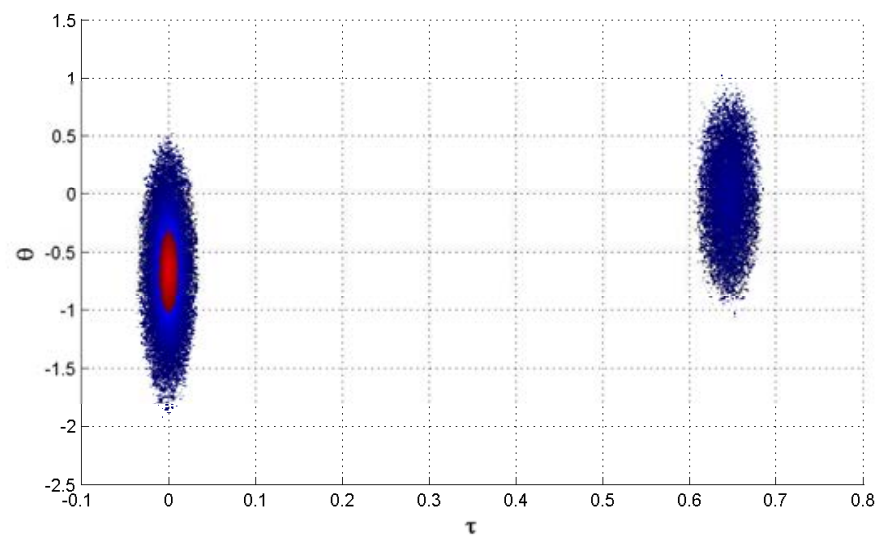

(b) Income $\geq \$ 50,000,<\$ 100,000$

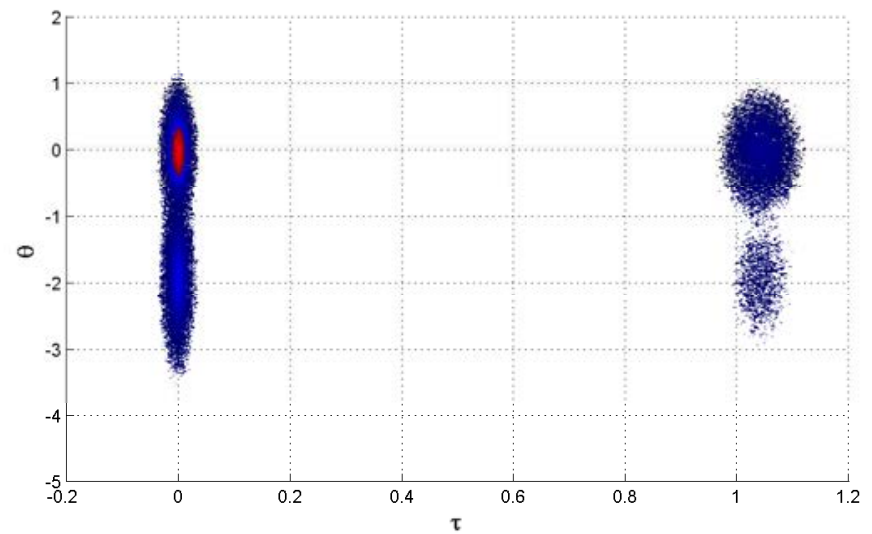

(c) Income $\geq \$ 100,000$

Figure 5. Joint Density of $\tau$ and $\theta$.

Colored areas correspond to the regions with a positive density above a small cut-off value (1e-5). Red areas correspond to the regions with the highest density. 


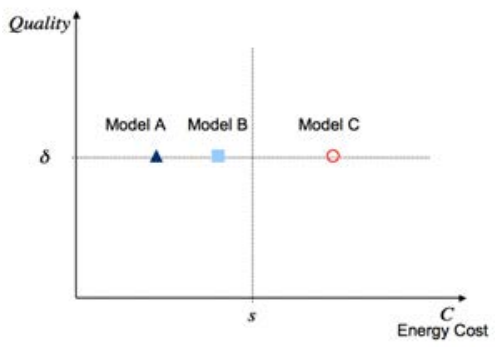

(a)

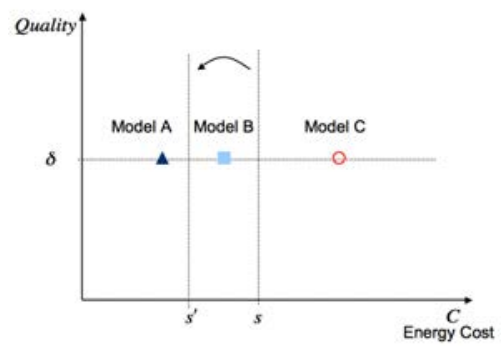

(d)

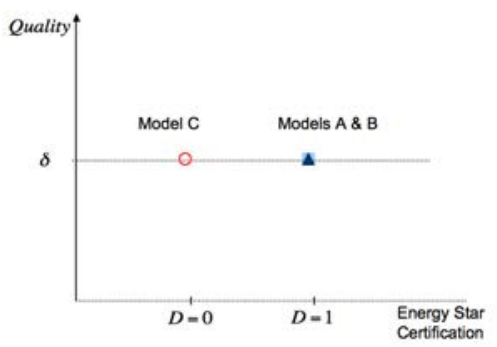

(b)

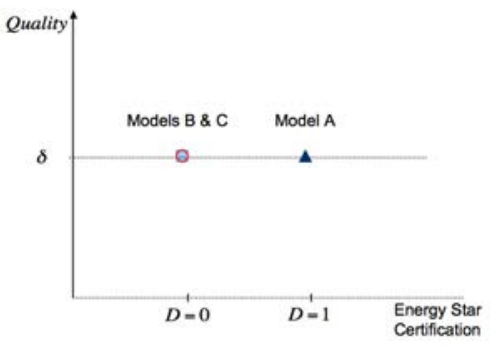

(e)

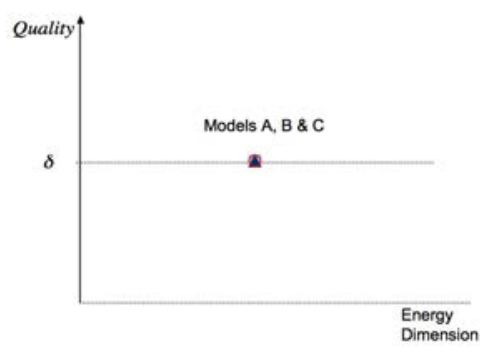

(c)

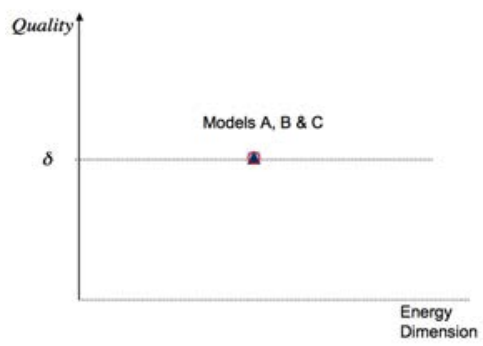

(f)

Figure 6. (a) Consumers with expectations about energy costs for each model. $s$ represents the ES standard. (b) Consumers that rely on ES. $D=1$ models certified ES, zero otherwise. (c) Consumers that Dismiss Energy Costs. (d)-(f) Change in consumer preferences after revision of the ES standard $s \rightarrow s^{\prime}$. 


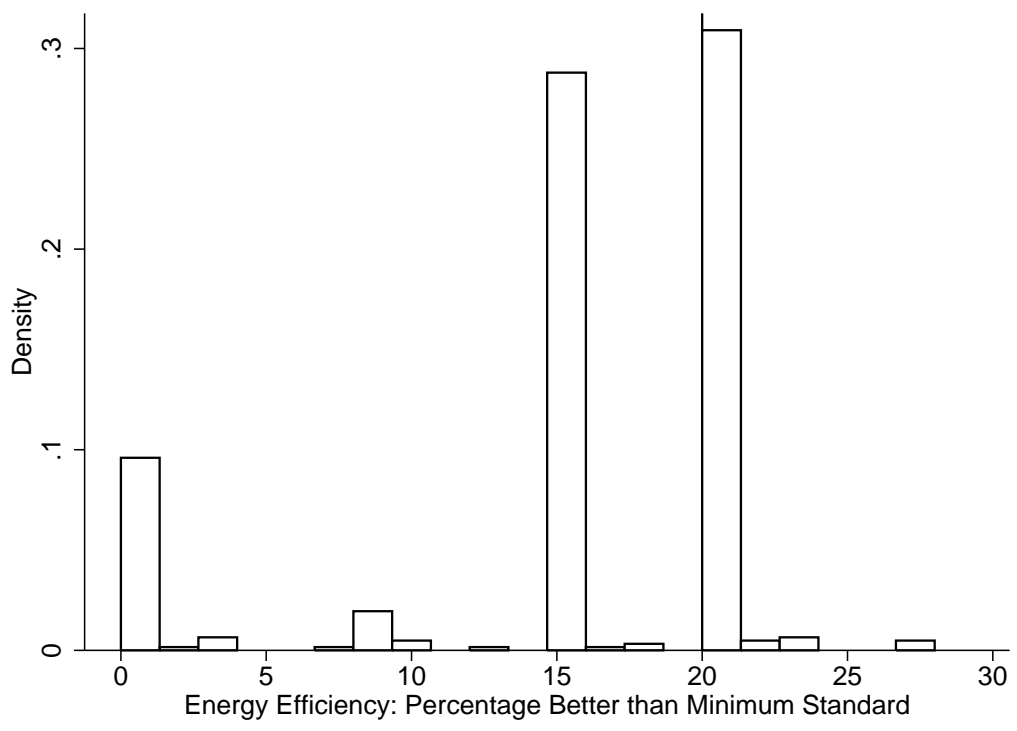

(a)

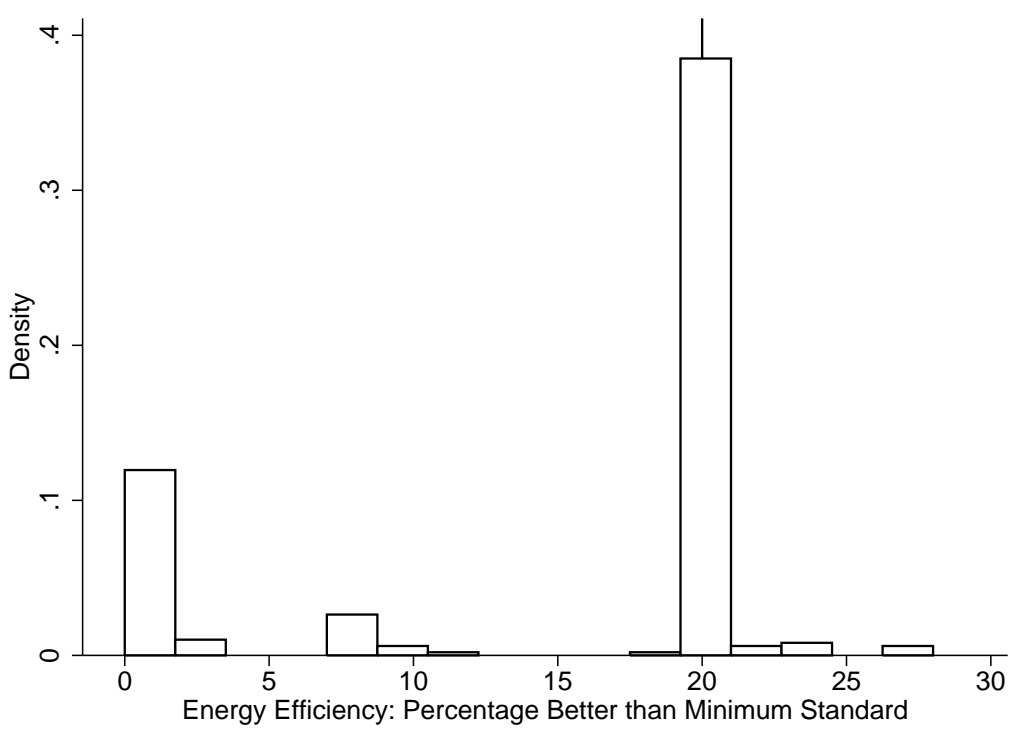

(b)

Figure 7. Choice Sets for Policy Analysis

Each panel corresponds to the density of the energy efficiency levels of all refrigerator models offered. The $\mathrm{x}$-axis is the percentage difference in energy efficiency relative to the federal minimum energy efficiency standards. In the second panel, all products meeting the ES certification requirement prior April 2008 were excluded from the choice set. 


\section{Tables}

TABle 1. Summary Statistics

\begin{tabular}{lcc}
\hline \hline & 2008 & 2010 \\
Choice Set & & \\
Nb of Refrigerator Models, US Market & 2,524 & 1,496 \\
Nb of Decertified Refrigerator Models, US Market & 1,278 & 21 \\
Nb of Refrigerator Models, Sample & 1,483 & 1,174 \\
Nb of Decertified Refrigerator Models in Restricted Sample & 674 & 14 \\
Average Size of Choice Set (Store-Trimester) & 99 & 92 \\
SD Size of Choice Set (Store-Trimester) & 44 & 37 \\
Price & & \\
Avg Promotional Price & $\$ 1,325$ & $\$ 1,411$ \\
SD Promotional Price Offered & $\$ 639$ & $\$ 693$ \\
Avg Promotion & $11 \%$ & $15 \%$ \\
Avg Duration of a Promotion & $1.4 \mathrm{week}$ & $3.1 \mathrm{week}$ \\
Avg Promotional Price ENERGY STAR & $\$ 1,426$ & $\$ 1,368$ \\
Avg Promotional Price Non-ENERGY STAR & $\$ 1,240$ & $\$ 1,472$ \\
Avg Promotional Price Decertified Model & $\$ 1,416$ & $\$ 2,468$ \\
Rebate & & \\
Nb of Utility Rebate Programs for ENERGY STAR refrigerators & 87 & 133 \\
Nb of State Rebate Programs for ENERGY STAR refrigerators & 0 & 44 \\
Avg Rebate Offered & $\$ 48$ & $\$ 104$ \\
SD Rebate Offered & $\$ 54$ & $\$ 144$ \\
Electricity Costs: US Refrigerators & & \\
Avg Elec. Price (County) & & \\
Max Elec. Price & $0.113 \$ / \mathrm{kWh}$ & $0.113 \$ / \mathrm{kWh}$ \\
Min Elec. Price & $0.03 \$ / \mathrm{kWh}$ \\
Avg Elec. Consumption & $0.420 \$ / \mathrm{kWh}$ & $0.03 \$ / \mathrm{kWh}$ \\
Avg Elec. Consumption ENERGY STAR & $520 \mathrm{kWh} / \mathrm{y}$ & $506 \mathrm{kWh} / \mathrm{y}$ \\
Avg Elec. Consumption Decertified ENERGY STAR & $500 \mathrm{kWh} / \mathrm{y}$ & $501 \mathrm{kWh} / \mathrm{y}$ \\
Avg Elec. Consumption Non-ENERGY STAR & $520 \mathrm{kWh} / \mathrm{y}$ & $547 \mathrm{kWh} / \mathrm{y}$ \\
\hline \hline
\end{tabular}

Notes: The restricted sample consists of all transactions made by homeowners living in single family housing units that bought no more than one refrigerator in any given year. The number of full-size refrigerator models for the whole US was obtained from the US EPA. According to the FTC data, there were 2,693 full-size refrigerators offered on the US market in 2008. 
TABle 2. Conditional Logit

\begin{tabular}{lccccc}
\hline \hline & $(\mathbf{I})$ & $(\mathbf{I I})$ & $(\mathbf{I I I})$ & $(\mathbf{I V})$ & $(\mathbf{V})$ \\
& CL & CL & CL & CL & CL \\
& Base & Brand-Week & State Elec. Price & $2009-2011$ & $2009-2010$ \\
\hline Price $(\hat{\eta})$ & $-0.421^{* * *}$ & $-0.402^{* * *}$ & $-0.422^{* * *}$ & $-0.273^{* *}$ & $-0.318^{* * *}$ \\
& $(0.010)$ & $(0.010)$ & $(0.010)$ & $(0.099)$ & $(0.007)$ \\
Elect. Cost $(\hat{\theta})$ & $-0.681^{* * *}$ & $-0.666^{* * *}$ & $-1.304^{* * *}$ & -1.279 & $-1.497^{* * *}$ \\
& $(0.167)$ & $(0.166)$ & $(0.151)$ & $(2.203)$ & $(0.208)$ \\
Rebate $(\hat{\psi})$ & 0.006 & 0.005 & 0.004 & $0.025^{*}$ & $0.046^{* * *}$ \\
& $(0.015)$ & 0.015 & $(0.015)$ & $(0.012)$ & $(0.014)$ \\
ENERGY STAR $(\hat{\tau})$ & $0.080^{* *}$ & $0.101^{* *}$ & $0.099^{* *}$ & 0.245 & 0.091 \\
& $(0.029)$ & $(0.013)$ & $(0.013)$ & $(1.419)$ & $(0.049)$ \\
Interpretation & & & & & \\
Price Elasticity & -5.47 & -5.23 & -5.49 & -3.55 & -4.13 \\
WTP ES $\tau / \eta(\$)$ & 19.0 & 25.2 & 23.4 & 89.6 & 28.6 \\
Prob. Take Rebate $\psi / \eta$ & 0.01 & 0.01 & 0.01 & 0.09 & 0.14 \\
Implied Discount Rate & 0.62 & 0.60 & 0.32 & 0.21 & 0.21 \\
\hline Product FE & Yes & Yes & Yes & Yes & Yes \\
Brand-Week FE & No & Yes & No & No & No \\
Avg Elec Price & County & County & State & County & County \\
Nb Obs & 201,509 & 201,509 & 201,509 & 184,645 & 74,300 \\
Nb Clusters & 922 & 922 & 922 & 913 & 912 \\
\hline \hline Note: Stangar & & & & \\
\hline
\end{tabular}

Note: Standard errors clustered at the store level in parentheses: $\dagger(p<0.10)^{*}$ $(p<0.05),{ }^{* *}(p<0.01),{ }^{* * *}(p<0.001)$. 
TABLE 3. Conditional Logit by Income Group

\begin{tabular}{|c|c|c|c|c|c|c|}
\hline \multirow[b]{2}{*}{ Price } & \multicolumn{2}{|r|}{$\begin{array}{l}\text { Income } \\
<\$ 50,000\end{array}$} & \multicolumn{2}{|c|}{$\begin{array}{c}\text { Income } \\
\geq \$ 50,000 \& \\
<\$ 100,000\end{array}$} & \multicolumn{2}{|c|}{$\begin{array}{c}\text { Income } \\
\geq \$ 100,000\end{array}$} \\
\hline & $\begin{array}{c}-0.561^{* * *} \\
(0.021)\end{array}$ & $\begin{array}{c}-0.561^{* * *} \\
(0.020)\end{array}$ & $\begin{array}{c}-0.459^{* * *} \\
(0.011)\end{array}$ & $\begin{array}{c}-0.458^{* * *} \\
(0.011)\end{array}$ & $\begin{array}{c}-0.363^{* * *} \\
(0.010)\end{array}$ & $\begin{array}{c}-0.363^{* * *} \\
(0.010)\end{array}$ \\
\hline Elect. Cost & $\begin{array}{l}-0.315^{*} \\
(0.126)\end{array}$ & $\begin{array}{c}-0.327^{* *} \\
(0.126)\end{array}$ & $\begin{array}{c}-0.562^{* * *} \\
(0.170)\end{array}$ & $\begin{array}{c}-0.563^{* * *} \\
(0.169)\end{array}$ & $\begin{array}{c}-0.988^{* * *} \\
(0.251)\end{array}$ & $\begin{array}{c}-0.989^{* * *} \\
(0.251)\end{array}$ \\
\hline Rebate & $\begin{array}{l}0.063^{* *} \\
(0.022)\end{array}$ & $\begin{array}{c}0.073^{* * *} \\
(0.021)\end{array}$ & $\begin{array}{c}0.020 \\
(0.017)\end{array}$ & $\begin{array}{c}0.020 \\
(0.016)\end{array}$ & $\begin{array}{l}-0.025 \\
(0.018)\end{array}$ & $\begin{array}{l}-0.023 \\
(0.018)\end{array}$ \\
\hline ENERGY STAR & $\begin{array}{c}0.072^{* * *} \\
(0.018)\end{array}$ & $\begin{array}{c}-0.107 \\
(0.0607)\end{array}$ & $\begin{array}{c}0.087^{* * *} \\
(0.020)\end{array}$ & $\begin{array}{c}-0.273^{* * *} \\
(0.051)\end{array}$ & $\begin{array}{c}0.134^{* * *} \\
(0.021)\end{array}$ & $\begin{array}{c}0.015 \\
(0.058)\end{array}$ \\
\hline \multicolumn{7}{|l|}{ ENERGY STAR } \\
\hline X Educ College & & $\begin{array}{c}-0.080^{* * *} \\
(0.023)\end{array}$ & & $\begin{array}{l}-0.010 \\
(0.017)\end{array}$ & & $\begin{array}{l}-0.004 \\
(0.018)\end{array}$ \\
\hline X Educ Graduate & & $\begin{array}{c}0.151^{* * *} \\
(0.042)\end{array}$ & & $\begin{array}{l}0.082^{* *} \\
(0.026)\end{array}$ & & $\begin{array}{c}0.028 \\
(0.021)\end{array}$ \\
\hline X Income $+\$ 16.5 \mathrm{~K}$ & & $\begin{array}{c}0.165^{* * *} \\
(0.030)\end{array}$ & & $\begin{array}{c}0.086^{* * *} \\
(0.025)\end{array}$ & & $\begin{array}{c}0.032 \\
(0.020)\end{array}$ \\
\hline X Income $+\$ 33 \mathrm{~K}$ & & $\begin{array}{c}0.184^{* * *} \\
(0.026)\end{array}$ & & $\begin{array}{c}0.210^{* * *} \\
(0.022)\end{array}$ & & $\begin{array}{l}-0.007 \\
(0.019)\end{array}$ \\
\hline $\mathrm{X}$ Age $>30, \leq 45$ & & $\begin{array}{c}0.096^{*} \\
(0.046)\end{array}$ & & $\begin{array}{l}0.116^{* *} \\
(0.039)\end{array}$ & & $\begin{array}{l}0.093^{*} \\
(0.042)\end{array}$ \\
\hline $\mathrm{X}$ Age $>45, \leq 55$ & & $\begin{array}{c}0.012 \\
(0.050)\end{array}$ & & $\begin{array}{c}0.039 \\
(0.037)\end{array}$ & & $\begin{array}{c}0.051 \\
(0.043)\end{array}$ \\
\hline X Age $>55, \leq 70$ & & $\begin{array}{l}0.146^{* *} \\
(0.045)\end{array}$ & & $\begin{array}{c}0.136^{* * *} \\
(0.038)\end{array}$ & & $\begin{array}{c}0.058 \\
(0.043)\end{array}$ \\
\hline X Age $>70$ & & $\begin{array}{c}0.050 \\
(0.045)\end{array}$ & & $\begin{array}{c}0.136^{* * *} \\
(0.041)\end{array}$ & & $\begin{array}{l}-0.017 \\
(0.047)\end{array}$ \\
\hline X FamSize 2 & & $\begin{array}{c}0.183^{* * *} \\
(0.034)\end{array}$ & & $\begin{array}{c}0.231^{* * *} \\
(0.026)\end{array}$ & & $\begin{array}{c}0.130^{* * *} \\
(0.033)\end{array}$ \\
\hline X FamSize 3 or 4 & & $\begin{array}{c}0.199^{* * *} \\
(0.034)\end{array}$ & & $\begin{array}{c}0.247^{* * *} \\
(0.026)\end{array}$ & & $\begin{array}{c}0.117^{* * *} \\
(0.031)\end{array}$ \\
\hline $\mathrm{X}$ FamSize 5 or more & & $\begin{array}{c}0.220^{* * *} \\
(0.038)\end{array}$ & & $\begin{array}{c}0.200^{* * *} \\
(0.027)\end{array}$ & & $\begin{array}{l}0.086^{* *} \\
(0.033)\end{array}$ \\
\hline X Political Democrat & & $\begin{array}{c}-0.157^{* * *} \\
(0.035)\end{array}$ & & $\begin{array}{c}-0.101^{* * *} \\
(0.024)\end{array}$ & & $\begin{array}{l}-0.059^{*} \\
(0.023)\end{array}$ \\
\hline X Political Others & & $\begin{array}{c}-0.175^{* * *} \\
(0.031)\end{array}$ & & $\begin{array}{c}-0.119^{* * *} \\
(0.022)\end{array}$ & & $\begin{array}{c}-0.066^{* *} \\
(0.023)\end{array}$ \\
\hline \multicolumn{7}{|l|}{ Interpretation } \\
\hline Price Elasticity & -7.29 & -7.54 & -5.97 & -5.97 & -4.72 & -4.72 \\
\hline WTP ES $\tau / \eta(\$)$ & 12.7 & varies with demo. & 18.9 & varies with demo. & 36.9 & varies with demo. \\
\hline Prob. Take Rebate $\psi / \eta$ & 0.11 & 0.13 & 0.04 & 0.04 & -0.07 & -0.07 \\
\hline Implied Discount Rate & 1.78 & 1.82 & 0.82 & 0.82 & 0.37 & 0.37 \\
\hline Nb Obs. & 49,279 & & 76,115 & & 76,115 & \\
\hline Nb Clusters & 922 & & 922 & & 922 & \\
\hline
\end{tabular}

Note: Standard errors clustered at the zipcode level in parentheses: ${ }^{*}(p<0.05)$,

${ }^{* *}(p<0.01),{ }^{* * *}(p<0.001)$. 
TABle 4. Conditional Logit by Income Group, contd.

\begin{tabular}{|c|c|c|c|c|c|c|}
\hline \multirow[b]{2}{*}{ Price } & \multicolumn{2}{|c|}{$\begin{array}{l}\text { Income } \\
<\$ 50,000\end{array}$} & \multicolumn{2}{|c|}{$\begin{aligned} & \text { Income } \\
\geq & \$ 50,000 \& \\
< & \$ 100,000\end{aligned}$} & \multicolumn{2}{|c|}{$\begin{array}{c}\text { Income } \\
\geq \$ 100,000\end{array}$} \\
\hline & $\begin{array}{c}-0.561^{* * *} \\
(0.020)\end{array}$ & & $\begin{array}{c}-0.459^{* * *} \\
(0.011)\end{array}$ & & $\begin{array}{c}-0.363^{* * *} \\
(0.010)\end{array}$ & \\
\hline Elect. Cost & $\begin{array}{c}0.045 \\
(0.297)\end{array}$ & & $\begin{array}{l}-0.452 \\
(0.274)\end{array}$ & & $\begin{array}{l}0.857^{*} \\
(0.351)\end{array}$ & \\
\hline Rebate & $\begin{array}{c}0.073^{* * *} \\
(0.021)\end{array}$ & & $\begin{array}{c}0.021 \\
(0.016)\end{array}$ & & $\begin{array}{l}-0.022 \\
(0.018)\end{array}$ & \\
\hline ENERGY STAR & $\begin{array}{l}-0.090 \\
(0.060)\end{array}$ & & $\begin{array}{c}-0.263^{* * *} \\
(0.051)\end{array}$ & & $\begin{array}{c}0.050 \\
(0.058)\end{array}$ & \\
\hline Interactions: & Elect. Cost & $\begin{array}{c}\text { ENERGY } \\
\text { STAR }\end{array}$ & Elect. Cost & $\begin{array}{c}\text { ENERGY } \\
\text { STAR }\end{array}$ & Elect. Cost & $\begin{array}{c}\text { ENERGY } \\
\text { STAR }\end{array}$ \\
\hline X Educ College & $\begin{array}{l}-0.038 \\
(0.093)\end{array}$ & $\begin{array}{c}-0.081^{* * *} \\
(0.023)\end{array}$ & $\begin{array}{c}-0.044 \\
(0.079)\end{array}$ & $\begin{array}{l}-0.011 \\
(0.017)\end{array}$ & $\begin{array}{c}-0.284^{* * *} \\
(0.086)\end{array}$ & $\begin{array}{c}-0.009 \\
(0.018)\end{array}$ \\
\hline X Educ Graduate & $\begin{array}{c}0.012 \\
(0.201)\end{array}$ & $\begin{array}{c}0.149^{* * *} \\
(0.043)\end{array}$ & $\begin{array}{c}-0.377^{* *} \\
(0.120)\end{array}$ & $\begin{array}{l}0.075^{* *} \\
(0.027)\end{array}$ & $\begin{array}{c}-0.454^{* * *} \\
(0.113)\end{array}$ & $\begin{array}{c}0.021 \\
(0.021)\end{array}$ \\
\hline $\mathrm{X}$ Income $+\$ 16.5 \mathrm{~K}$ & $\begin{array}{c}0.232 \\
(0.121)\end{array}$ & $\begin{array}{c}0.169^{* * *} \\
(0.030)\end{array}$ & $\begin{array}{c}0.458^{* * *} \\
(0.114)\end{array}$ & $\begin{array}{c}0.095^{* * *} \\
(0.025)\end{array}$ & $\begin{array}{c}0.001 \\
(0.099)\end{array}$ & $\begin{array}{c}0.032 \\
(0.020)\end{array}$ \\
\hline $\mathrm{X}$ Income $+\$ 33 \mathrm{~K}$ & $\begin{array}{c}0.404^{* * *} \\
(0.103)\end{array}$ & $\begin{array}{c}0.190^{* * *} \\
(0.026)\end{array}$ & $\begin{array}{c}0.460^{* * *} \\
(0.100)\end{array}$ & $\begin{array}{c}0.219^{* * *} \\
(0.022)\end{array}$ & $\begin{array}{l}-0.214^{*} \\
(0.095)\end{array}$ & $\begin{array}{c}-0.011 \\
(0.019)\end{array}$ \\
\hline $\mathrm{X}$ Age $>30, \leq 45$ & $\begin{array}{c}0.036 \\
(0.176)\end{array}$ & $\begin{array}{l}0.098^{*} \\
(0.047)\end{array}$ & $\begin{array}{c}-0.093 \\
(0.153)\end{array}$ & $\begin{array}{l}0.115^{* *} \\
(0.039)\end{array}$ & $\begin{array}{l}-0.312 \\
(0.195)\end{array}$ & $\begin{array}{l}0.084^{*} \\
(0.043)\end{array}$ \\
\hline $\mathrm{X}$ Age $>45, \leq 55$ & $\begin{array}{c}-0.867^{* * *} \\
(0.179)\end{array}$ & $\begin{array}{l}-0.008 \\
(0.050)\end{array}$ & $\begin{array}{c}-0.912^{* * *} \\
(0.156)\end{array}$ & $\begin{array}{c}0.015 \\
(0.037)\end{array}$ & $\begin{array}{c}-1.078^{* * *} \\
(0.203)\end{array}$ & $\begin{array}{c}0.024 \\
(0.044)\end{array}$ \\
\hline X Age $>55, \leq 70$ & $\begin{array}{c}-2.081^{* * *} \\
(0.175)\end{array}$ & $\begin{array}{l}0.110^{*} \\
(0.045)\end{array}$ & $\begin{array}{c}-2.356^{* * *} \\
(0.164)\end{array}$ & $\begin{array}{l}0.088^{*} \\
(0.038)\end{array}$ & $\begin{array}{c}-2.391^{* * *} \\
(0.203)\end{array}$ & $\begin{array}{c}0.014 \\
(0.044)\end{array}$ \\
\hline $\mathrm{X}$ Age $>70$ & $\begin{array}{c}-3.919^{* * *} \\
(0.188)\end{array}$ & $\begin{array}{c}0.002 \\
(0.045)\end{array}$ & $\begin{array}{c}-3.813^{* * *} \\
(0.189)\end{array}$ & $\begin{array}{c}0.075 \\
(0.042)\end{array}$ & $\begin{array}{c}-3.781^{* * *} \\
(0.240)\end{array}$ & $\begin{array}{l}-0.070 \\
(0.047)\end{array}$ \\
\hline X FamSize 2 & $\begin{array}{c}0.609^{* * *} \\
(0.158)\end{array}$ & $\begin{array}{c}0.192^{* * *} \\
(0.034)\end{array}$ & $\begin{array}{c}0.565^{* * *} \\
(0.129)\end{array}$ & $\begin{array}{c}0.242^{* * *} \\
(0.027)\end{array}$ & $\begin{array}{l}-0.266 \\
(0.175)\end{array}$ & $\begin{array}{c}0.127^{* * *} \\
(0.033)\end{array}$ \\
\hline X FamSize 3 or 4 & $\begin{array}{c}1.084^{* * *} \\
(0.149)\end{array}$ & $\begin{array}{c}0.213^{* * *} \\
(0.034)\end{array}$ & $\begin{array}{c}0.806^{* * *} \\
(0.124)\end{array}$ & $\begin{array}{c}0.257^{* * *} \\
(0.026)\end{array}$ & $\begin{array}{l}-0.027 \\
(0.170)\end{array}$ & $\begin{array}{c}0.116^{* * *} \\
(0.030)\end{array}$ \\
\hline X FamSize 5 or more & $\begin{array}{c}1.389^{* * *} \\
(0.169)\end{array}$ & $\begin{array}{c}0.239^{* * *} \\
(0.038)\end{array}$ & $\begin{array}{c}1.098^{* * *} \\
(0.139)\end{array}$ & $\begin{array}{c}0.221^{* * *} \\
(0.027)\end{array}$ & $\begin{array}{l}-0.016 \\
(0.179)\end{array}$ & $\begin{array}{l}0.085^{* *} \\
(0.033)\end{array}$ \\
\hline X Political Democrat & $\begin{array}{l}-0.145 \\
(0.160)\end{array}$ & $\begin{array}{c}-0.160^{* * *} \\
(0.035)\end{array}$ & $\begin{array}{l}-0.023 \\
(0.119)\end{array}$ & $\begin{array}{c}-0.102^{* * *} \\
(0.024)\end{array}$ & $\begin{array}{l}-0.195 \\
(0.120)\end{array}$ & $\begin{array}{c}-0.062^{* *} \\
(0.023)\end{array}$ \\
\hline X Political Others & $\begin{array}{l}-0.102 \\
(0.148)\end{array}$ & $\begin{array}{c}-0.178^{* * *} \\
(0.032)\end{array}$ & $\begin{array}{l}0.339^{* *} \\
(0.114)\end{array}$ & $\begin{array}{c}-0.113^{* * *} \\
(0.022)\end{array}$ & $\begin{array}{c}0.200 \\
(0.123)\end{array}$ & $\begin{array}{c}-0.063^{* *} \\
(0.023)\end{array}$ \\
\hline $\begin{array}{l}\text { Nb Obs. } \\
\text { Nb Clusters }\end{array}$ & $\begin{array}{c}49,279 \\
922\end{array}$ & & $\begin{array}{c}76,115 \\
922\end{array}$ & & $\begin{array}{c}76,115 \\
922\end{array}$ & \\
\hline
\end{tabular}

Notes: Standard errors clustered at the store level. ${ }^{*}(p<0.05),{ }^{* *}(p<0.01)$, *** $(p<0.001)$ 
TABLE 5. Information Acquisition Model: 2008

\begin{tabular}{|c|c|c|c|c|c|c|}
\hline & \multicolumn{2}{|c|}{$\begin{array}{l}\text { Income } \\
<\$ 50,000\end{array}$} & \multicolumn{2}{|c|}{$\begin{aligned} & \text { Income } \\
\geq & \$ 50,000 \& \\
< & \$ 100,000\end{aligned}$} & \multicolumn{2}{|c|}{$\begin{array}{c}\text { Income } \\
\geq \$ 100,000\end{array}$} \\
\hline \multicolumn{7}{|c|}{ Behavioral Parameters Purchase Decision: } \\
\hline Price $(\hat{\eta})$ & $-0.543^{* * *}$ & $(0.001)$ & $-0.448^{* * *}$ & $(0.001)$ & $-0.357^{* * *}$ & $(0.001)$ \\
\hline ENERGY STAR $\tau^{I}$ & $-0.312^{* * *}$ & $(0.065)$ & 0.008 & $(0.020)$ & $-0.064^{*}$ & $(0.030)$ \\
\hline ENERGY STAR $\tau^{E S}$ & $0.825^{* * *}$ & $(0.123)$ & $0.429^{* * *}$ & $(0.044)$ & $0.513^{* * *}$ & $(0.054)$ \\
\hline Rebate $(\hat{\psi})$ & $0.282^{* *}$ & $(0.112)$ & $0.132^{* *}$ & $(0.047)$ & 0.054 & $(0.043)$ \\
\hline Elec. Costs $(\hat{\theta})$ & $-5.197^{* * *}$ & $(0.407)$ & $-3.359^{* * *}$ & $(0.147)$ & $-3.861^{* * *}$ & $(0.224)$ \\
\hline$K^{h}$ & $-11.116^{* * *}$ & $(1.245)$ & $-8.124^{* * *}$ & $(1.634)$ & $-6.041^{* * *}$ & $(1.548)$ \\
\hline$K^{m}$ & $-2.368^{* *}$ & $(0.846)$ & $-3.928^{*}$ & $(1.864)$ & -1.336 & $(1.544)$ \\
\hline Educ College $\left(\beta_{I}\right)$ & 0.155 & $(0.189)$ & 0.273 & $(0.278)$ & 0.288 & $(0.235)$ \\
\hline Educ Graduate $\left(\beta_{I}\right)$ & 0.205 & $(0.426)$ & $1.941^{* * *}$ & $(0.469)$ & 0.578 & $(0.262)$ \\
\hline FamSize $\left(\beta_{I}\right)$ & $-0.325^{* * *}$ & $(0.060)$ & $-0.477^{* * *}$ & $(0.077)$ & $-0.180^{* *}$ & $(0.056)$ \\
\hline Age $\left(\beta_{I}\right)$ & $0.185^{* * *}$ & $(0.018)$ & $0.207^{* * *}$ & $(0.020)$ & $0.166^{* * *}$ & $(0.015)$ \\
\hline Political Democrat $\left(\beta_{I}\right)$ & $-0.560^{*}$ & $(0.332)$ & $-0.958^{* *}$ & $(0.409)$ & $-0.785^{* *}$ & $(0.333)$ \\
\hline Political Others $\left(\beta_{I}\right)$ & -0.490 & $(0.328)$ & $-1.992^{* * *}$ & $(0.420)$ & $-1.057^{* *}$ & $(0.329)$ \\
\hline Educ College $\left(\beta_{E S}\right)$ & -0.052 & $(0.268)$ & $0.695^{*}$ & $(0.359)$ & 0.301 & $(0.256)$ \\
\hline Educ Graduate $\left(\beta_{E S}\right)$ & $1.439^{* * *}$ & $(0.369)$ & $2.477^{* * *}$ & $(0.502)$ & 0.405 & $(0.291)$ \\
\hline FamSize $\left(\beta_{E S}\right)$ & 0.081 & $(0.064)$ & -0.020 & $(0.088)$ & $-0.166^{* *}$ & $(0.061)$ \\
\hline Age $\left(\beta_{E S}\right)$ & $0.042^{* * *}$ & $(0.009)$ & $0.061^{* * *}$ & $(0.015)$ & $0.056^{* * *}$ & $(0.012)$ \\
\hline Political Democrat $\left(\beta_{E S}\right)$ & $-1.310^{* * *}$ & $(0.332)$ & $-1.368^{* *}$ & $(0.457)$ & $-1.235^{* * *}$ & $(0.333)$ \\
\hline Political Others $\left(\beta_{E S}\right)$ & $-1.581^{* * *}$ & $(0.333)$ & $-2.041^{* * *}$ & $(0.449)$ & $-1.313^{* * *}$ & $(0.318)$ \\
\hline mean-ElecCost & $-2.663^{* *}$ & $(0.969)$ & $3.209^{* *}$ & $(1.417)$ & -1.294 & $(1.066)$ \\
\hline var-ElecCost & -3.426 & $(4.983)$ & $-30.029^{* * *}$ & $(8.911)$ & 3.275 & $(6.569)$ \\
\hline Nb Models $\left(\gamma^{I}\right)$ & 0.013 & $(0.008)$ & 0.004 & $(0.005)$ & 0.005 & $(0.003)$ \\
\hline Variance Price $\left(\gamma^{I}\right)$ & 0.034 & $(0.061)$ & -0.185 & $(0.135)$ & -0.040 & $(0.131)$ \\
\hline Variance $\mathrm{FE}\left(\gamma^{I}\right)$ & -0.197 & $(0.125)$ & 0.156 & $(0.384)$ & -0.603 & $(0.463)$ \\
\hline Proportion-Estar & $2.667^{* * *}$ & $(0.805)$ & $6.817^{* * *}$ & $(1.350)$ & $2.677^{* * *}$ & $(0.702)$ \\
\hline $\mathrm{Nb}$ Models $\left(\gamma^{E S}\right)$ & $-0.090^{* * *}$ & $(0.017)$ & $-0.048^{* * *}$ & $(0.009)$ & $-0.024^{* * *}$ & $(0.005)$ \\
\hline Variance Price $\left(\gamma^{E S}\right)$ & 0.067 & $(0.066)$ & 0.245 & $(0.161)$ & 0.127 & $(0.126)$ \\
\hline Variance $\mathrm{FE}\left(\gamma^{E S}\right)$ & -0.089 & $(0.135)$ & -0.293 & $(0.454)$ & -0.255 & $(0.432)$ \\
\hline \multicolumn{7}{|l|}{ Interpretation } \\
\hline Own-Price Elasticity & -7.1 & & -5.8 & & -4.6 & \\
\hline Implicit Discount Rate & 0.08 & & 0.11 & & 0.06 & \\
\hline WTP ES Label, $e=I(\$)$ & -57.4 & & 1.9 & & -18.0 & \\
\hline WTP ES Label, $e=E S(\$)$ & 151.8 & & 95.8 & & 143.8 & \\
\hline Prob. Taking Rebate & 0.52 & & 0.29 & & 0.15 & \\
\hline$Q(e=I)$ & 0.19 & & 0.34 & & 0.30 & \\
\hline$Q(e=E S)$ & 0.16 & & 0.24 & & 0.37 & \\
\hline$Q(e=U)$ & 0.65 & & 0.41 & & 0.33 & \\
\hline Nb Obs. & 49,279 & & 76,115 & & 76,115 & \\
\hline
\end{tabular}

Notes: In the estimation, estimated product fixed effects enter the individual choice probabilities, and are treated as data. Standard errors are obtained using the Murphy and Topel's approach $(1985) .{ }^{*}(p<0.05),{ }^{* *}(p<0.01),{ }^{* * *}(p<0.001)$ 
TABLE 6. The Opportunity Cost of Imperfect Energy Information

\begin{tabular}{|c|c|c|c|}
\hline & $\begin{array}{c}\begin{array}{c}\text { Perfectly Informed } \\
\text { vs } \\
\text { Information Acquisition }\end{array}\end{array}$ & $\begin{array}{c}\text { Perfectly Informed } \\
\text { vs } \\
\text { Uninformed }\end{array}$ & $\begin{array}{c}\text { Perfectly Informed } \\
\text { vs } \\
\text { ENERGY STAR }\end{array}$ \\
\hline \multicolumn{4}{|c|}{ Consumer Surplus with Label Effect (\$) } \\
\hline Income $<\$ 50,000$ & 25 & 33 & 18 \\
\hline$\geq \$ 50,000 \&<\$ 100,000$ & 14 & 21 & 19 \\
\hline$\geq \$ 100,000$ & 20 & 32 & 26 \\
\hline All Income & 19 & 28 & 21 \\
\hline \multicolumn{4}{|c|}{ Consumer Surplus without Label Effect (\$) } \\
\hline Income $<\$ 50,000$ & 36 & 40 & 56 \\
\hline$\geq \$ 50,000 \&<\$ 100,000$ & 15 & 20 & 28 \\
\hline$\geq \$ 100,000$ & 26 & 32 & 46 \\
\hline All Income & 24 & 29 & 42 \\
\hline \multicolumn{4}{|l|}{$\mathrm{kWh} /$ year purchased } \\
\hline & -18 & -26 & -24 \\
\hline \multicolumn{4}{|l|}{ Externality Costs $(\$)$} \\
\hline & -14 & -21 & -19 \\
\hline \multicolumn{4}{|l|}{ Producer Surplus (\$) } \\
\hline & -21 & -22 & -47 \\
\hline \multicolumn{4}{|l|}{ Welfare $(\$)$} \\
\hline with label & 12 & 27 & -7 \\
\hline without label & 17 & 28 & 14 \\
\hline
\end{tabular}

Notes: In each column, a choice model is compared to a model where all consumers are perfectly informed. The first column compares the outcomes obtained with the information acquisition model. The second column compares a choice model where all consumers are uninformed. The third column compares a choice model where all consumers rely on ENERGY STAR. The table shows that the consumers surplus decreases in all cases when consumers are not perfectly informed, but profits increase. The externality costs increase under imperfect information. 


\section{Online Appendix}

\section{Appendix A. Comparative Statics Results}

Information Acquisition Costs. Naturally, we should expect that consumers will collect and process more energy information the lower the costs to do so. In particular, a consumer should always choose to be fully informed if there are no extra costs. The present model is consistent with this intuition, whether ENERGY STAR information is available or not.

Proposition 1. (i) Suppose that ENERGY STAR information is not available. If $\mathcal{K}(e=$ $U)=\mathcal{K}(e=I)$, it is optimal for the consumer to select $e=h$.

(ii) Suppose that ENERGY STAR information is available. If $\mathcal{K}(e=U)=\mathcal{K}(e=E S)=\mathcal{K}(e=$ $I)$, it is optimal for the consumer to select $e=I$. Moreover, if $\mathcal{K}(e=U)=\mathcal{K}(e=E S)$, $e=E S$ is strictly better than $e=U$ for the consumer.

Proof. This is true by the fact that the expectation of the maximum of random variables is always greater that the maximum of their expectations. In particular, consider some set of random variables $\left\{Y_{1}, Y_{2}, \ldots, Y_{k}\right\}$. The distribution of $\max _{1 \leq j \leq k}\left\{Y_{j}\right\}$ (first order) stochastically dominates the distribution of $Y_{l}$ for any $l \in\{1, \ldots, k\}$. This implies that $E\left[\max _{1 \leq j \leq k} Y_{j}\right] \geq E\left[Y_{l}\right]$ for $l=1, \ldots, k$, and thus,

$$
E\left[\max _{1 \leq j \leq k} Y_{j}\right] \geq \max _{1 \leq j \leq k} E\left[Y_{j}\right]
$$

To show (i), it suffices to show that

$$
E_{\epsilon, \mathcal{C}}\left[\max _{j}\left\{U_{i j}\left(\delta_{j}, \eta P_{j}, C_{j}, \epsilon_{i j}\right)\right\}\right] \geq E_{\epsilon}\left[\max _{j}\left\{E_{\mathcal{C}}\left[U_{i j}\left(\delta_{j}, \eta P_{j}, C_{j}, \epsilon_{i j}\right)\right]\right\}\right],
$$

which implies that (i) holds for $K=0$. I show a stronger inequality; in particular, that for any $\epsilon_{i j}$,

$$
E_{\mathcal{C}}\left[\max _{j}\left\{U_{i j}\left(\delta_{j}, \eta P_{j}, C_{j}, \epsilon_{i j}\right)\right\}\right] \geq\left[\max _{j}\left\{E_{\mathcal{C}}\left[U_{i j}\left(\delta_{j}, \eta P_{j}, C_{j}, \epsilon_{i j}\right)\right]\right\}\right] .
$$

This follows from (14) if I set

$$
Y_{j} \equiv U_{i j}\left(\delta_{j}, \eta P_{j}, C_{j}, \epsilon_{i j}\right)
$$


This concludes the proof for (i).

The proof for (ii) is similar.

Crowding-Out Effect. A simple, but important implication to the above result is that if the costs of processing and collecting ENERGY STAR information are lower than the costs of searching for energy costs, some consumers may prefer to select the maximum level of effort than to not collect information at all, but could prefer a medium level of effort than a maximum one. Formally,

Corollary 1. If $\mathcal{K}(e=E S)<\mathcal{K}(e=I)$, then for some consumers

$$
\mathcal{V}(e=U)<\mathcal{V}(e=I)<\mathcal{V}(e=E S)
$$

Proof. The proof follows directly from Proposition 1.

This formally shows that the ENERGY STAR certification induces some consumers to be less informed and crowds out efforts to fully account for energy costs.

Uncertainty about Energy Costs. The present model stipulates that uncertainty in beliefs is the main driver that induces consumers to search for energy information. Therefore, the model should predict that the larger the uncertainty in beliefs, the more likely consumers are to search.

I now show this result. I focus on the case that consumers' beliefs become more uncertain, but remain unbiased. This scenario is notably consistent with Allcott (2011)'s findings that shows that consumers' beliefs about future gas prices are on average unbiased, but largely uncertain.

Consider the following definition. Beliefs about $X$ represented by a distribution $\hat{F}$ are more uncertain that beliefs $F$ if $F$ second order stochastically dominates $\hat{F}$ :

$$
\int_{\underline{x}}^{b} F(x) d x \geq \int_{\underline{x}}^{b} \hat{F}(x) d x
$$

for all $b$. 
Proposition 2. If $\hat{X}_{j} \sim \hat{F}, \forall j$ and $X_{j} \sim F, \forall j$, with $\int_{\underline{x}}^{b} F(x) d x \geq \int_{\underline{x}}^{b} \hat{F}(x) d x$ for all $b$, then

$$
E_{\epsilon, \mathcal{X}, S}\left[\max _{j}\left\{U_{i j}\left(\delta_{j}, \eta P_{j}, X_{j}(S), d, \epsilon_{i j}\right)\right\} \mid \mathcal{I}(e)\right] \geq E_{\epsilon, \hat{\mathcal{X}}, S}\left[\max _{j}\left\{U_{i j}\left(\delta_{j}, \eta P_{j}, \hat{X}_{j}(S), d, \epsilon_{i j}\right)\right\} \mid \mathcal{I}(e)\right]
$$

Proof. First note that by the definition of second order stochastically dominance, if $X_{j}$ second-order stochastically dominates $\hat{X}_{j}$, and if $X_{j}$ and $\hat{X}_{j}$ have the same mean, then $E\left[h\left(X_{j}\right)\right] \geq E\left[h\left(\hat{X}_{j}\right)\right]$ for all concave function $h$. Given that the maximum is a concave function, I then have $E\left[h\left(X_{j}, Y\right)\right] \geq$ $E\left[h\left(\hat{X}_{j}, Y\right)\right]$ for any variable $Y$.

Proposition 2 simply says that the larger the variance in energy costs, the higher is the value of information. This also implies that ENERGY STAR will lead to more sub-optimal choices, in expectation, in choice sets where products are largely disperse in the energy efficiency characteristics space. 


\section{Appendix B. Data Cleaning and Manipulation}

Creating a Random Sample. To perform the estimation of the demand model, a random subsample of the transactions is used. The sub-sample is constructed as follow.

First, the sub-sample is drawn from the set of transactions that fit the following criteria (the restricted sample):

- transactions made by consumers that are homeowners;

- transactions made by consumers living in single family housing units; and

- transactions made by consumers that made no more that one refrigerator purchase in any given year.

Second, the following stratified sampling method is used to create the sub-sample. For a given targeted sample size, I sample transactions for three different income groups:

- households with income of less than $\geq \$ 50,000$;

- households with income between $\$ 50,000$ and $\$ 100,000$;

- and households with income of more than $\$ 100,000$.

Average Electricity Prices. The use of average electricity prices is partly motivated by recent empirical evidence (Borenstein (2010), Ito (2012)) that suggests that electricity consumers may in fact respond to variation in average prices, more than marginal prices. In the present case, the use of average electricity prices is also dictated by the fact that household's location is not perfectly known. Therefore, it is impossible to match households with their exact electricity tariff and infer marginal price.

Average electricity prices at the county level are computed as follow. Using form EIA-861 of the Energy Information Administration, I compute the average residential electric price for each electric utility operating in the US for the years 2008. I then match electric utility territories with each of the county where I sampled at least one store. For counties with only one electric utility, I 
use the average electricity price for this particular utility. For counties with several electric utilities, I take the arithmetic mean of each utility average price to construct the county level price.

\section{Appendix C. Alternative Estimators}

The Average Consumer. Adding an outside option to the conditional logit, I obtain a linear expression for the market shares in region $r$ at time $t$ (Berry 1994):

$$
\ln \left(q_{j r t}\right)=\tau D_{j t}-\eta P_{j r t}+\psi R_{r t} X D_{j t}-\theta C_{j r}+\gamma_{j}+\alpha_{r}+\alpha_{t}+\zeta_{j r t}
$$

where $q_{j r t}$ is the quantity of refrigerator model $j$ sold during week $t$ in store $r$, and $\zeta_{j r t}$ is a marketspecific unobservable. Not all refrigerator models sell every week in every store, the dependent variable thus takes the value zero for a large number of observations. Equation 16 is then estimated with a negative binomial model. The sample used for the estimation consists of all transactions observed during the period 2007-2009. Stores with a low number of sales were excluded, which left 545 stores for the estimation. Price time series for each refrigerator model are week and store specific. The choice set are store and month specific, and constructed using the same methodology than for the conditional logit model.

In the first specification, product, week, and store fixed effects are included, and the electricity prices averaged at the county level are used. The estimate of the price coefficient corresponds to an own-price elasticity of -2.89 , which is about half the elasticity obtained with the conditional logit model. The present price elasticity has a different interpretation here given that an outside option has been added, and can be interpreted as being long-run. The size of the label effect is 0.041 , and corresponds to a WTP for the ENERGY STAR label of $18 \$$. This replicates closely the estimate obtained with the condition logit $(19 \$)$. The effect of rebate is negative and not significant. The estimate of the coefficient on electricity costs is negative and significant, and implies a discount rate of $41 \%$, which is lower than for the conditional logit model $(62 \%)$.

The second specification replace the week fixed effects, with brand-week fixed effects. Like in the conditional logit model, it has few effects on the price coefficient, suggesting that marketing 
efforts are not an important source of bias. The coefficient for the ENERGY STAR label is larger under this specification.

The third specification uses electricity prices averaged at the state level. This impacts the coefficient on electricity costs. The coefficient still negative and significant, but implies a discount rate of $29 \%$. Similar than in the condition logit model, measurement error in how electricity prices are measured has an important effect.

The fourth specification includes store-year fixed effects. This provides a better control for any region specific unobservables. Doing so has few impact on the coefficients.

Interaction with Demographics. Table 8 presents the results from a conditional logit model where the coefficient on prices is interacted with demographic information, in addition of the coefficients on electricity costs, and ENERGY STAR dummy. The results complement Table 4, and show that the main patterns hold. 
TABLE 7. Negative Binomial Model

\begin{tabular}{|c|c|c|c|c|}
\hline & $(\mathbf{I})$ & 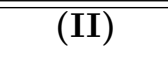 & (III) & (IV) \\
\hline Price $(\hat{\eta})$ & $\begin{array}{c}-0.222^{* * *} \\
(0.006)\end{array}$ & $\begin{array}{c}-0.219^{* * *} \\
(0.006)\end{array}$ & $\begin{array}{l}-.219^{* * *} \\
(.006)\end{array}$ & $\begin{array}{c}-0.219^{* * *} \\
(0.006)\end{array}$ \\
\hline ENERGY STAR $(\hat{\tau})$ & $\begin{array}{c}0.041^{* * *} \\
(0.009)\end{array}$ & $\begin{array}{c}0.076^{* * *} \\
(0.010)\end{array}$ & $\begin{array}{l}.075^{* * *} \\
(.010)\end{array}$ & $\begin{array}{c}0.077^{* * *} \\
(0.010)\end{array}$ \\
\hline Rebate $(\hat{\psi})$ & $\begin{array}{l}-0.011 \\
(0.013)\end{array}$ & $\begin{array}{l}-0.012 \\
(.013)\end{array}$ & $\begin{array}{l}-.010 \\
(.013)\end{array}$ & $\begin{array}{l}-0.013 \\
(0.014)\end{array}$ \\
\hline Elect. Cost $(\hat{\theta})$ & $\begin{array}{c}-.532^{* * *} \\
(0.115)\end{array}$ & $\begin{array}{c}-0.533^{* * *} \\
(.115)\end{array}$ & $\begin{array}{l}-.740^{* * *} \\
(0.088)\end{array}$ & $\begin{array}{c}-0.543^{* * *} \\
(0.120)\end{array}$ \\
\hline Product FE & Yes & Yes & Yes & Yes \\
\hline ZipCode FE & Yes & Yes & Yes & Yes \\
\hline Week FE & Yes & No & No & No \\
\hline BrandXWeek FE & No & Yes & Yes & Yes \\
\hline Avg. Elec. Price & County & County & State & County \\
\hline $\begin{array}{l}\text { Observations } \\
\text { Nb Clusters }\end{array}$ & $\begin{array}{c}9.50 \mathrm{e}+06 \\
545\end{array}$ & $\begin{array}{c}9.50 \mathrm{e}+06 \\
545\end{array}$ & $\begin{array}{c}9.50 \mathrm{e}+06 \\
545\end{array}$ & $\begin{array}{c}9.50 \mathrm{e}+06 \\
545\end{array}$ \\
\hline \multicolumn{5}{|c|}{ Interpretation: TO UPDATE } \\
\hline Price Elasticity & -2.89 & -2.85 & -2.85 & -2.85 \\
\hline WTP ES $\tau / \eta$ & 18.0 & 34.7 & 34.2 & 35.2 \\
\hline Prob. Take Rebate $\psi / \eta$ & -0.05 & -0.05 & -0.05 & -0.06 \\
\hline Implied Discount Rebate & 0.417 & 0.410 & 0.293 & 0.402 \\
\hline
\end{tabular}


58

TABLE 8. Conditional Logit: Interaction with Demographics

\begin{tabular}{|c|c|c|c|c|c|c|c|c|c|}
\hline \multirow[b]{2}{*}{ Price } & \multicolumn{3}{|c|}{$\begin{array}{l}\text { Income } \\
<\$ 50,000\end{array}$} & \multicolumn{3}{|c|}{$\begin{array}{c}\text { Income } \\
\geq \$ 50,000 \& \\
<\$ 100,000\end{array}$} & \multicolumn{3}{|c|}{$\begin{array}{c}\text { Income } \\
\geq \$ 100,000\end{array}$} \\
\hline & $\begin{array}{c}-0.586^{* * *} \\
(0.022)\end{array}$ & & & $\begin{array}{c}-0.496^{* * *} \\
(0.013)\end{array}$ & & & \begin{tabular}{|c}
$-0.404^{* * *}$ \\
$(0.012)$
\end{tabular} & & \\
\hline Elect. Cost & $\begin{array}{c}0.445 \\
(0.320)\end{array}$ & & & $\begin{array}{c}0.222 \\
(0.287)\end{array}$ & & & $\begin{array}{c}1.643^{* * *} \\
(0.361)\end{array}$ & & \\
\hline Rebate & $\begin{array}{c}0.073^{* * *} \\
(0.021)\end{array}$ & & & $\begin{array}{c}0.020 \\
(0.016)\end{array}$ & & & $\begin{array}{l}-0.022 \\
(0.018)\end{array}$ & & \\
\hline ENERGY STAR & $\begin{array}{l}0.0179 \\
(0.074)\end{array}$ & & & $\begin{array}{l}-0.051 \\
(0.063)\end{array}$ & & & $\begin{array}{c}0.313^{* * *} \\
(0.069)\end{array}$ & & \\
\hline Interactions: & $\begin{array}{l}\text { Elect. } \\
\text { Cost }\end{array}$ & $\begin{array}{c}\text { ENERGY } \\
\text { STAR }\end{array}$ & Price & $\begin{array}{c}\text { Elect. } \\
\text { Cost }\end{array}$ & $\begin{array}{c}\text { ENERGY } \\
\text { STAR }\end{array}$ & Price & $\begin{array}{c}\text { Elect. } \\
\text { Cost }\end{array}$ & $\begin{array}{c}\text { ENERGY } \\
\text { STAR }\end{array}$ & Price \\
\hline X Educ College & $\begin{array}{c}0.011 \\
(0.101)\end{array}$ & $\begin{array}{l}-0.066^{*} \\
(0.027)\end{array}$ & $\begin{array}{l}-0.003 \\
(0.003)\end{array}$ & $\begin{array}{l}-0.076 \\
(0.086)\end{array}$ & $\begin{array}{l}-0.020 \\
(0.021)\end{array}$ & $\begin{array}{c}0.001 \\
(0.002)\end{array}$ & \begin{tabular}{|c}
$-0.473^{* * *}$ \\
$(0.092)$
\end{tabular} & $\begin{array}{c}-0.065^{* *} \\
(0.022)\end{array}$ & $\begin{array}{r}0.008^{* * *} \\
(0.002)\end{array}$ \\
\hline X Educ Grad & $\begin{array}{l}-0.445 \\
(0.230)\end{array}$ & $\begin{array}{c}0.016 \\
(0.051)\end{array}$ & $\begin{array}{c}0.024^{* * *} \\
(0.005)\end{array}$ & $\begin{array}{c}-0.733^{* * *} \\
(0.129)\end{array}$ & $\begin{array}{l}-0.030 \\
(0.031)\end{array}$ & $\begin{array}{c}0.017^{* * *} \\
(0.003)\end{array}$ & $\begin{array}{c}-0.737^{* * *} \\
(0.121)\end{array}$ & $\begin{array}{l}-0.060^{*} \\
(0.025)\end{array}$ & $\begin{array}{c}0.012^{* * *} \\
(0.002)\end{array}$ \\
\hline $\mathrm{X}$ Inc $+\$ 16.5 \mathrm{~K}$ & $\begin{array}{l}-0.030 \\
(0.138)\end{array}$ & $\begin{array}{l}0.088^{*} \\
(0.036)\end{array}$ & $\begin{array}{c}0.015^{* * *} \\
(0.004)\end{array}$ & $\begin{array}{l}0.255^{*} \\
(0.124)\end{array}$ & $\begin{array}{c}0.037 \\
(0.030)\end{array}$ & $\begin{array}{c}0.010^{* * *} \\
(0.003)\end{array}$ & $\begin{array}{c}-0.308^{* *} \\
(0.106)\end{array}$ & $\begin{array}{l}-0.059^{*} \\
(0.024)\end{array}$ & $\begin{array}{c}0.013^{* * *} \\
(0.002)\end{array}$ \\
\hline $\mathrm{X}$ Inc $+\$ 33 \mathrm{~K}$ & $\begin{array}{c}0.215 \\
(0.116)\end{array}$ & $\begin{array}{c}0.132^{* * *} \\
(0.030)\end{array}$ & $\begin{array}{l}0.011^{* *} \\
(0.003)\end{array}$ & $\begin{array}{l}-0.072 \\
(0.111)\end{array}$ & $\begin{array}{l}0.055^{*} \\
(0.026)\end{array}$ & $\begin{array}{c}0.027^{* * *} \\
(0.002)\end{array}$ & $\begin{array}{c}-0.759^{* * *} \\
(0.107)\end{array}$ & $\begin{array}{c}-0.167^{* * *} \\
(0.021)\end{array}$ & $\begin{array}{c}0.023^{* * *} \\
(0.002)\end{array}$ \\
\hline X Age $>30, \leq 45$ & $\begin{array}{l}-0.350 \\
(0.197)\end{array}$ & $\begin{array}{l}-0.034 \\
(0.056)\end{array}$ & $\begin{array}{c}0.024^{* * *} \\
(0.006)\end{array}$ & $\begin{array}{c}-0.444^{* *} \\
(0.161)\end{array}$ & $\begin{array}{l}-0.010 \\
(0.044)\end{array}$ & $\begin{array}{c}0.020^{* * *} \\
(0.004)\end{array}$ & $\begin{array}{c}-0.826^{* * *} \\
(0.201)\end{array}$ & $\begin{array}{l}-0.089 \\
(0.051)\end{array}$ & $\begin{array}{c}0.025^{* * *} \\
(0.004)\end{array}$ \\
\hline X Age $>45, \leq 55$ & $\begin{array}{c}-1.114^{* * *} \\
(0.198)\end{array}$ & $\begin{array}{l}-0.088 \\
(0.058)\end{array}$ & $\begin{array}{l}0.014^{*} \\
(0.006)\end{array}$ & $\begin{array}{c}-1.053^{* * *} \\
(0.164)\end{array}$ & $\begin{array}{l}-0.034 \\
(0.043)\end{array}$ & $\begin{array}{l}0.008^{*} \\
(0.004)\end{array}$ & $\begin{array}{c}-1.366^{* * *} \\
(0.208)\end{array}$ & $\begin{array}{l}-0.077 \\
(0.052)\end{array}$ & $\begin{array}{c}0.015^{* * *} \\
(0.004)\end{array}$ \\
\hline $\mathrm{X}$ Age $>55, \leq 70$ & $\begin{array}{c}-2.304^{* * *} \\
(0.194)\end{array}$ & $\begin{array}{c}0.042 \\
(0.053)\end{array}$ & $\begin{array}{l}0.013^{*} \\
(0.005)\end{array}$ & $\begin{array}{c}-2.592^{* * *} \\
(0.174)\end{array}$ & $\begin{array}{l}0.0010 \\
(0.044)\end{array}$ & $\begin{array}{c}0.013^{* * *} \\
(0.004)\end{array}$ & $\begin{array}{c}-2.520^{* * *} \\
(0.208)\end{array}$ & $\begin{array}{l}-0.043 \\
(0.053)\end{array}$ & $\begin{array}{l}0.008^{*} \\
(0.004)\end{array}$ \\
\hline X Age $>70$ & $\begin{array}{c}-3.392^{* * *} \\
(0.206)\end{array}$ & $\begin{array}{l}0.137^{*} \\
(0.054)\end{array}$ & $\begin{array}{c}-0.026^{* * *} \\
(0.006)\end{array}$ & $\begin{array}{c}-3.425^{* * *} \\
(0.196)\end{array}$ & $\begin{array}{c}0.164^{* * *} \\
(0.047)\end{array}$ & $\begin{array}{c}-0.015^{* * *} \\
(0.004)\end{array}$ & $\begin{array}{c}-3.127^{* * *} \\
(0.240)\end{array}$ & $\begin{array}{c}0.072 \\
(0.057)\end{array}$ & $\begin{array}{c}-0.021^{* * *} \\
(0.005)\end{array}$ \\
\hline X FamSize 2 & $\begin{array}{c}0.342 \\
(0.177)\end{array}$ & $\begin{array}{c}0.109^{* *} \\
(0.042)\end{array}$ & $\begin{array}{c}0.015^{* *} \\
(0.005)\end{array}$ & $\begin{array}{c}0.331^{*} \\
(0.139)\end{array}$ & $\begin{array}{c}0.168^{* * *} \\
(0.032)\end{array}$ & $\begin{array}{c}0.012^{* * *} \\
(0.003)\end{array}$ & $\begin{array}{c}-0.588^{* *} \\
(0.179)\end{array}$ & $\begin{array}{c}0.025 \\
(0.039)\end{array}$ & $\begin{array}{c}0.015^{* * *} \\
(0.003)\end{array}$ \\
\hline X FamSize 3-4 & $\begin{array}{c}0.628^{* * *} \\
(0.168)\end{array}$ & $\begin{array}{c}0.074 \\
(0.041)\end{array}$ & $\begin{array}{c}0.026^{* * *} \\
(0.004)\end{array}$ & $\begin{array}{c}0.436^{* *} \\
(0.136)\end{array}$ & $\begin{array}{c}0.140^{* * *} \\
(0.032)\end{array}$ & $\begin{array}{c}0.019^{* * *} \\
(0.003)\end{array}$ & $\begin{array}{c}-0.480^{* *} \\
(0.175)\end{array}$ & $\begin{array}{c}-0.021 \\
(0.037)\end{array}$ & $\begin{array}{c}0.020^{* * *} \\
(0.003)\end{array}$ \\
\hline X FamSize $5+$ & $\begin{array}{c}0.817^{* * *} \\
(0.183)\end{array}$ & $\begin{array}{c}0.060 \\
(0.046)\end{array}$ & $\begin{array}{c}0.033^{* * *} \\
(0.005)\end{array}$ & $\begin{array}{c}0.750^{* * *} \\
(0.152)\end{array}$ & $\begin{array}{c}0.112^{* * *} \\
(0.033)\end{array}$ & $\begin{array}{c}0.018^{* * *} \\
(0.003)\end{array}$ & $\begin{array}{c}-0.364^{*} \\
(0.183)\end{array}$ & $\begin{array}{l}-0.021 \\
(0.038)\end{array}$ & $\begin{array}{c}0.016^{* * *} \\
(0.003)\end{array}$ \\
\hline X Pol Dem. & $\begin{array}{c}0.080 \\
(0.187)\end{array}$ & $\begin{array}{c}-0.098^{*} \\
(0.042)\end{array}$ & $\begin{array}{c}-0.011^{*} \\
(0.005)\end{array}$ & $\begin{array}{c}0.224 \\
(0.130)\end{array}$ & $\begin{array}{l}-0.030 \\
(0.028)\end{array}$ & $\begin{array}{c}-0.012^{* * *} \\
(0.002)\end{array}$ & $\begin{array}{c}0.047 \\
(0.129)\end{array}$ & $\begin{array}{c}0.004 \\
(0.026)\end{array}$ & $\begin{array}{c}-0.009^{* * *} \\
(0.002)\end{array}$ \\
\hline X Pol Others & $\begin{array}{c}0.150 \\
(0.174)\end{array}$ & $\begin{array}{c}-0.106^{* *} \\
(0.039)\end{array}$ & $\begin{array}{c}-0.013^{* *} \\
(0.004)\end{array}$ & $\begin{array}{c}0.558^{* * *} \\
(0.123)\end{array}$ & $\begin{array}{l}-0.049 \\
(0.027)\end{array}$ & $\begin{array}{c}-0.011^{\text {*** }} \\
(0.002)\end{array}$ & $\begin{array}{l}0.413^{* *} \\
(0.132)\end{array}$ & $\begin{array}{l}-0.003 \\
(0.025)\end{array}$ & $\begin{array}{c}-0.009^{* * *} \\
(0.002)\end{array}$ \\
\hline
\end{tabular}

Notes: Standard errors clustered at the store level. ${ }^{*}(p<0.05),{ }^{* *}(p<0.01)$,

*** $(p<0.001)$ 


\section{Appendix D. FKRB's Estimator}

The FKRB's estimator models the CDF of the random parameters as a mixture of point masses. Alternatively, FKRB propose to estimate a smooth density by modeling the distribution of the parameters as a mixture of normal densities. This requires to specify $M$ normal basis functions with a predetermined mean and variance, and use simulation to construct the estimator.

In particular, the $m^{\text {th }}$ basis function is defined as the product of the marginals of the $K$ random parameters:

$$
N\left(\beta \mid \mu^{m}, \sigma^{m}\right)=\prod_{k=1}^{K} N\left(\beta \mid \mu_{k}^{m}, \sigma_{k}^{m}\right)
$$

The simulated choice probability is thus given by:

$$
Q_{i j r t} \approx \sum_{m}^{M} \alpha_{m}\left(\frac{1}{S} \sum_{s=1}^{S} P_{i j r t \mid \beta^{m, s}}^{m}\right)
$$

where $\beta^{m, s}$ is the $s^{t h}$ draw from the $r^{\text {th }}$ normal basis. The estimate of $\alpha$ is thus given by:

$$
\hat{\alpha}=\operatorname{argmin}_{\alpha} \frac{1}{N J} \sum_{i=1}^{I} \sum_{j=1}^{J}\left(y_{i j r t}-\sum_{m}^{M} \alpha_{m}\left(\frac{1}{S} \sum_{s=1}^{S} P_{i j r t \mid \beta^{m, s}}^{m}\right)\right)
$$

s.t.

$$
\sum_{m}^{M} \alpha_{m}=1, \alpha_{m} \geq 0
$$

For the present application, $\eta, \psi$ and $\gamma_{j}$ are taken as data, and they are fixed at the MLE estimates (Model 1, Table 2). The joint density of the parameters $\theta$ and $\tau$ is a mixture of $M=108$ normal basis functions. To construct the basis functions, 9 marginals for the parameter $\theta$, and 11 marginals for the parameter $\tau$ are used. The means of the marginals are defined relative to the MLE estimates of the coefficients $\hat{\tau}$ and $\hat{\theta}$. In particular, the means of the marginals for the parameter $\theta$ is the vector: $[2.25 \hat{\theta}, 2 \hat{\theta}, 1.75 \hat{\theta}, 1.25 \hat{\theta}, \hat{\theta}, 0.75 \hat{\theta}, 0.5 \hat{\theta}, 0.25 \hat{\theta}, 0.05 \hat{\theta}]$. The means of the marginals for the parameter $\tau$ is the vector: $[8 \hat{\tau}, 6 \hat{\tau}, 4 \hat{\tau}, 2.5 \hat{\tau}, 1.75 \hat{\tau}, 1.25 \hat{\tau}, \hat{\tau}, 0.75 \hat{\tau}, 0.5 \hat{\tau}, 0.25 \hat{\tau}, 0]$. For each marginal, 
the standard deviation is set to a small value corresponding to $0.1 \%$ of the mean of the marginal. The estimation is carried with the matlab package lsqlin. 


\section{Appendix E. Policy Analysis}

\section{E.1. Emission Factors}

TABle 9. Emission Factors and Externality Costs

\begin{tabular}{|c|c|c|c|}
\hline \multicolumn{4}{|c|}{ Non-baseload Output Emission Rates (U.S. Average) } \\
\hline Pollutant & Estimate & & Source \\
\hline CO2 & $1,583 \mathrm{lb} / \mathrm{MWh}$ & & \multirow{5}{*}{ USEPA, eGRID2007 } \\
\hline $\mathrm{CH} 4^{a}$ & $35.8 \mathrm{lb} / \mathrm{GWh}$ & & \\
\hline$N 2 O^{a}$ & $19.9 \mathrm{lb} / \mathrm{GWh}$ & & \\
\hline SO2 & $6.13 \mathrm{lb} / \mathrm{MWh}$ & & \\
\hline$N O x$ & $2.21 \mathrm{lb} / \mathrm{MWh}$ & & \\
\hline \multicolumn{4}{|c|}{ Damage Cost $(2008 \$)$} \\
\hline Pollutant & Low Estimate & High Estimate & Source \\
\hline $\mathrm{CO} 2$ & $\$ 21.8 / \mathrm{t}$ & $\$ 67.1 / \mathrm{t}$ & Greenstone, Kopits and Wolverton (2011) \\
\hline SO2 & $\$ 2,060 / \mathrm{t}$ & $\$ 6,700 / \mathrm{t}$ & low: Muller and Mendelsohn (2012), high: USEPA ${ }^{b}$ \\
\hline$N O x$ & $\$ 380 / \mathrm{t}$ & $\$ 4,591 / \mathrm{t}$ & low: Muller and Mendelsohn (2012), high: DOE $^{c}$ \\
\hline \multicolumn{4}{|c|}{$\begin{array}{l}\text { Notes: (a) Externality costs associated to } \mathrm{CH} 4 \text { and } N 2 \mathrm{O} \text { are assumed to be the same than for } \mathrm{CO} 2 \text {. CH4 and } \\
\mathrm{N} 2 \mathrm{O} \text { are converted in } \mathrm{CO} 2 \text { equivalent using estimates of global warming potential (GWP). The GWP used for } \mathrm{CH} 4 \\
\text { is } 25 \text {, and the GWP used for } N 2 \mathrm{O} \text { is } 298 \text {. Source: IPCC Fourth Assessment Report: Climate Change 2007. (b) } \\
\text { Estimate used in the illustrative analysis of the } 2012 \text { regulatory impact analysis for the proposed standards for electric } \\
\text { utility generating units. (c) Higher value of the estimate used in the Federal Rule for new minimum energy-efficiency } \\
\text { standards for refrigerators (1904-AB79). }\end{array}$} \\
\hline
\end{tabular}




\section{E.2. Sensitivity Tests}

TABLE 10. The Opportunity Cost of Imperfect Energy Information: Low Electricity Costs, No Rebate

\begin{tabular}{lccc}
\hline \hline & $\begin{array}{c}\text { Perfectly Informed } \\
\text { vs } \\
\text { Information Acquisition }\end{array}$ & $\begin{array}{c}\text { Perfectly Informed } \\
\text { vs } \\
\text { Uninformed }\end{array}$ & $\begin{array}{c}\text { Perfectly Informed } \\
\text { vs } \\
\text { ENERGY STAR }\end{array}$ \\
\hline Consumer Surplus with Label Effect $(\$)$ & 13 & 18 & 5 \\
Income $<\$ 50,000$ & 8 & 12 & 12 \\
$\geq \$ 50,000 \&<\$ 100,000$ & 11 & 18 & 13 \\
$\geq \$ 100,000$ & 10 & 16 & \\
All Income & 20 & & 32 \\
Consumer Surplus without Label Effect $(\$)$ & 24 & 20 \\
Income $<\$ 50,000$ & 9 & 12 & 27 \\
$\geq \$ 50,000 \&<\$ 100,000$ & 16 & 18 & -19 \\
$\geq \$ 100,000$ & 14 & 17 & -15 \\
All Income & & -21 & \\
kWh/year purchased & -14 & & -47 \\
Externality Costs $(\$)$ & -11 & -17 & -15 \\
Producer Surplus $(\$)$ & -21 & & 1 \\
Welfare $(\$)$ & & -22 & \\
with label & 8 & 15 & \\
without label & & 16 & \\
\hline \hline
\end{tabular}

Notes: In each column, a choice model is compared to a model where all consumers are perfectly informed. The first column compares the outcomes obtained with the information acquisition model. The second column compares a choice model where all consumers are uninformed. The third column compares a choice model where all consumers rely on ENERGY STAR. The table shows that the consumers surplus decreases in all cases when consumers are not perfectly informed, but profits increase. The externality costs increase under imperfect information. 
TABLE 11. The Opportunity Cost of Imperfect Energy Information: High Electricity Costs, $\$ 50$ Rebate

\begin{tabular}{|c|c|c|c|}
\hline & $\begin{array}{c}\text { Perfectly Informed } \\
\text { vs } \\
\text { Information Acquisition }\end{array}$ & $\begin{array}{c}\text { Perfectly Informed } \\
\text { vs } \\
\text { Uninformed }\end{array}$ & $\begin{array}{c}\text { Perfectly Informed } \\
\text { vs } \\
\text { ENERGY STAR }\end{array}$ \\
\hline \multicolumn{4}{|c|}{ Consumer Surplus with Label Effect (\$) } \\
\hline Income $<\$ 50,000$ & 52 & 63 & 41 \\
\hline$\geq \$ 50,000 \&<\$ 100,000$ & 31 & 44 & 39 \\
\hline$\geq \$ 100,000$ & 41 & 63 & 52 \\
\hline All Income & 40 & 56 & 45 \\
\hline \multicolumn{4}{|c|}{ Consumer Surplus without Label Effect (\$) } \\
\hline Income $<\$ 50,000$ & 60 & 67 & 72 \\
\hline$\geq \$ 50,000 \&<\$ 100,000$ & 31 & 42 & 49 \\
\hline$\geq \$ 100,000$ & 47 & 61 & 72 \\
\hline All Income & 44 & 55 & 63 \\
\hline \multicolumn{4}{|l|}{ kWh/year purchased } \\
\hline & -27 & -37 & -34 \\
\hline \multicolumn{4}{|l|}{ Externality Costs $(\$)$} \\
\hline & -11 & -17 & -15 \\
\hline \multicolumn{4}{|l|}{ Producer Surplus (\$) } \\
\hline & -30 & -30 & -59 \\
\hline \multicolumn{4}{|l|}{ Welfare $(\$)$} \\
\hline with label & 21 & 42 & 0 \\
\hline without label & 25 & 42 & 19 \\
\hline
\end{tabular}

Notes: In each column, a choice model is compared to a model where all consumers are perfectly informed. The first column compares the outcomes obtained with the information acquisition model. The second column compares a choice model where all consumers are uninformed. The third column compares a choice model where all consumers rely on ENERGY STAR. The table shows that the consumers surplus decreases in all cases when consumers are not perfectly informed, but profits increase. The externality costs increase under imperfect information. 
TABle 12. The Opportunity Cost of Imperfect Energy Information: No Bunching at Previous Certification Requirement

\begin{tabular}{lccc}
\hline \hline & $\begin{array}{c}\text { Perfectly Informed } \\
\text { vs } \\
\text { Information Acquisition }\end{array}$ & $\begin{array}{c}\text { Perfectly Informed } \\
\text { vs } \\
\text { Uninformed }\end{array}$ & $\begin{array}{c}\text { Perfectly Informed } \\
\text { vs }\end{array}$ \\
\hline ENERGY STAR \\
\hline Consumer Surplus with Label Effect $(\$)$ & & -20 \\
$\geq \$ 50,000 \&<\$ 100,000$ & 6 & 24 & 3 \\
$\geq \$ 100,000$ & 8 & 15 & 4 \\
All Income & 8 & 24 & -2 \\
Consumer Surplus without Label Effect $(\$)$ & 21 & 17 \\
Income $<\$ 50,000$ & 21 & & 11 \\
$\geq \$ 50,000$ \& $<\$ 100,000$ & 8 & 28 & 20 \\
$\geq \$ 100,000$ & 14 & 11 & 16 \\
All Income & 14 & 19 & -15 \\
kWh/year purchased & & & \\
Externality Costs $(\$)$ & -15 & -24 & -12 \\
Producer Surplus $(\$)$ & -12 & & -41 \\
Welfare $(\$)$ & -20 & -19 & -32 \\
with label & & & -14 \\
without label & -1 & 29 & \\
\hline \hline
\end{tabular}

Notes: In each column, a choice model is compared to a model where all consumers are perfectly informed. The first column compares the outcomes obtained with the information acquisition model. The second column compares a choice model where all consumers are uninformed. The third column compares a choice model where all consumers rely on ENERGY STAR. The table shows that the consumers surplus decreases in all cases when consumers are not perfectly informed, but profits increase. The externality costs increase under imperfect information. 